\title{
Inhibition of the BMP Signaling Pathway Ameliorated Established Clinical Symptoms of Experimental Autoimmune Encephalomyelitis
}

\author{
Herena Eixarch ${ }^{1,2}$. Laura Calvo-Barreiro ${ }^{1,2} \cdot$ Carme Costa $^{1,2} \cdot$ Gemma Reverter-Vives $^{1,2}$ - Mireia Castillo ${ }^{1,2}$. \\ Vanessa Gil $^{3,4,5,6}$ • José Antonio Del Río ${ }^{3,4,5,6} \cdot$ Xavier Montalban ${ }^{1,2,7} \cdot$ Carmen Espejo $^{1,2}$ (D)
}

Published online: 17 July 2020

(C) The American Society for Experimental NeuroTherapeutics, Inc. 2020

\begin{abstract}
Bone morphogenetic proteins (BMPs) are secreted growth factors that belong to the transforming growth factor beta superfamily. BMPs have been implicated in physiological processes, but they are also involved in many pathological conditions. Multiple sclerosis (MS) is an immune-mediated disease of the central nervous system (CNS); however, its etiology remains elusive. Some evidence points to BMPs as important players in the pathogenesis of inflammatory and autoimmune disorders. In the present work, we studied the expression of BMP2, BMP4, BMP5, BMP6, BMP7, BMP type II receptor, and noggin in the immune system during different phases of experimental autoimmune encephalomyelitis (EAE). Major changes in the expression of BMPs took place in the initial phases of EAE. Indeed, those changes mainly affected BMP6 (whose expression was abrogated), BMP2, and BMP7 (whose expression was increased). In addition, we showed that in vivo inhibition of the BMP signaling pathway with small molecules ameliorated the already established clinical symptoms of EAE, as well as the CNS histopathological features. At the immune level, we observed an expansion of plasmacytoid dendritic cells (pDCs) in mice treated with small molecules that inhibit the BMP signaling pathway. pDCs could play an important role in promoting the expansion of antigen-specific regulatory T cells. Altogether, our data suggest a role for BMPs in early immune events that take place in myelin oligodendrocyte glycoprotein (MOG)-induced EAE. In addition, the clinical outcome of the disease was improved when the BMP signaling pathway was inhibited in mice that presented established EAE symptoms.
\end{abstract}

Keywords Multiple sclerosis · Experimental autoimmune encephalomyelitis · Bone morphogenetic protein · Immune response · Dorsomorphin · DMH1

\section{Introduction}

Bone morphogenetic proteins (BMPs) are secreted growth factors that belong to the transforming growth factor beta (TGF- $\beta$ ) superfamily. In the canonical signaling pathway,

Carmen Espejo

carmen.espejo@vhir.org

1 Servei de Neurologia-Neuroimmunologia, Centre d'Esclerosi Múltiple de Catalunya, Vall d'Hebron Institut de Recerca, Hospital Universitari Vall d'Hebron, Barcelona, Spain

2 Universitat Autònoma de Barcelona, 08193 Bellaterra (Cerdanyola del Vallès), Spain

3 Molecular and Cellular Neurobiotechnology, Institute for Bioengineering of Catalonia (IBEC), The Barcelona Institute of Science and Technology (BIST), Parc Científic de Barcelona, Barcelona, Spain
BMPs bind to type II receptors and recruit type I receptors to form a receptor complex and signal through the cytoplasmic mediator SMAD1/5/8 [1]. Phosphorylated (p)SMAD1/5/8 translocates into the nucleus and regulates the transcription of BMP-dependent genes [2].

4 Department of Cell Biology, Physiology and Immunology, Universitat de Barcelona, Barcelona, Spain

5 Centro de Investigación Biomédica en Red sobre Enfermedades Neurodegenerativas (CIBERNED), Barcelona, Spain

6 Institute of Neuroscience, University of Barcelona, Barcelona, Spain

7 Division of Neurology, St Michael's Hospital, University of Toronto, Toronto, Canada 
BMPs have been implicated in various processes, including proliferation, survival, and cell fate, in several cell types and are involved in many pathological conditions [3], including multiple sclerosis (MS) [4-8]. MS is an immune-mediated neuroinflammatory disease of the central nervous system (CNS) that causes neurological disability in more than 2.5 million people worldwide. Neuroinflammation is the result of the infiltration of autoreactive $\mathrm{CD}^{+} \mathrm{T}$ cells and their interaction with local resident cells in the CNS, although a contribution of other immune cells has also been demonstrated [9]. The roles of BMPs in developmental and homeostatic processes of the CNS are widely known [10], but their roles in development of the thymus $[11,12]$ and T-cell differentiation have also been reported [13]. Indeed, BMPs are involved in the activation and polarization of naïve $\mathrm{CD}^{+} \mathrm{T}$ cells to $\mathrm{Th} 1$, Th17 and T regulatory (Treg) cells [14-17], suggesting a putative role in the regulation of adaptive immune responses. BMPs have also been reported to impact the homeostasis, differentiation, and function of various cells of the innate immune system. BMPs modulate the maturation of dendritic cells (DCs) as well as their capacity to release proinflammatory cytokines $[18,19]$. They also impact the differentiation and activation of macrophages in a dual manner, since BMP7 induces the polarization of macrophages to the alternative M2 phenotype [20], but BMP6 promotes the release of pro-inflammatory mediators in macrophages [21]. In addition, they support NK cell function [22] and restrain Bcell expansion and antibody production via different mechanisms depending on the BMP involved [23, 24]. Moreover, BMPs are also capable of modulating the immunosuppressive milieu in some pathogenic contexts, for example, blocking the anti-inflammatory activity of myeloid-derived suppressor cells (MDSCs) in breast cancer, thus inhibiting metastasis [25]. All these data strongly suggest a role for BMPs in the regulation of the immune response; however, the mechanisms that control the BMP signaling pathway are extremely complex, and the members of the BMP family carry out a variety of functions, making it difficult to answer the question of whether BMPs are beneficial or detrimental in the context of autoimmune diseases.

Although the expression of BMPs and some of their antagonists (i.e., noggin and follistatin) is reported to be altered in the CNS and peripheral immune system of MS patients [4-8] and in the CNS of EAE mice [26], there is a lack of information on the dynamics of BMP expression in the immune system in MS, which would provide important information about whether BMPs might be relevant therapeutic targets for MS treatment. In this study, we aimed to describe the changes in the expression of BMPs in the immune system of EAE mice in different phases of the disease and to test the therapeutic potential of targeting the BMP signaling pathway using inhibitory small molecules that specifically target the canonical signaling pathway of BMPs in myelin oligodendrocyte glycoprotein (MOG)-induced EAE mice that presented established clinical symptoms.

\section{Methods}

\section{Recombinant Proteins and Small Molecules}

For in vitro and in vivo experiments, murine recombinant BMP4, murine recombinant noggin (Peprotech, London, UK), dorsomorphin (DM; Abcam Biochemicals, Cambridge, UK) and dorsomorphin homologue 1 (DMH1; purchased from different sources: Merck Millipore, Billerica, USA; Tocris Bioscience, Bristol, UK; and Target Molecule Corp., Boston, USA) were used at the concentrations specified for each application.

The small inhibitory molecules DM and DMH1 inhibit phosphorylation of the cytoplasmic mediator SMAD1/5/8, with DMH1 being more specific than DM, which presents off-target effects on other signaling pathways [27].

\section{Jurkat Cells}

Jurkat cells (a human T-cell leukemia cell line) were cultured with RPMI (Biowest, Nuaillé, France) supplemented with $10 \% \mathrm{v} / \mathrm{v}$ HyClone ${ }^{\circledR}$ FetalClone I (Thermo Fisher Scientific, Waltham, MA, USA), $10 \mathrm{mM}$ Hepes, $2 \mathrm{mM}$ L-glutamine, $100 \mathrm{U} / \mathrm{ml}$ penicillin and $100 \mathrm{mg} / \mathrm{ml}$ streptomycin, all obtained from Gibco, Pasley, UK. To assess the activation and inhibition of the BMP signaling pathway, Jurkat cells were washed with $1 \times$ phosphate-buffered saline (PBS) and cultured for $3 \mathrm{~h}$ in serum-free X-VIVO 15 medium (Lonza, Basel, Switzerland) supplemented with $60 \mu \mathrm{M}$ 2-mercaptoethanol (Sigma-Aldrich, St. Louis, MO, USA), $2 \mathrm{mM}$ L-glutamine, $40 \mathrm{U} / \mathrm{ml}$ penicillin, and $40 \mathrm{mg} / \mathrm{ml}$ streptomycin, all obtained from Gibco. Then, BMP4 was added at a concentration of $500 \mathrm{ng} / \mathrm{ml}$ alone or together with the BMP antagonist noggin (500 ng/ml), DM $(1 \mu \mathrm{M})$, or DMH1 $(40 \mu \mathrm{M})$. After $30 \mathrm{~min}$ of culture, the cells were lysed to obtain the protein extract. Noggin and BMP4 were preincubated for $1 \mathrm{~h}$ at $37^{\circ} \mathrm{C}$ before being added to the culture.

\section{Western Blot}

Levels of phosphorylated (p)SMAD1/5 were determined in Jurkat cells. In vitro-treated Jurkat cells were homogenized in 1X RIPA buffer containing a proteinase inhibitor cocktail (Sigma-Aldrich), $200 \mathrm{mM}$ sodium orthovanadate, and $1 \mathrm{mM}$ sodium fluoride. Then, the samples were centrifuged at $15,000 \times \mathrm{g}$ for $20 \mathrm{~min}$ at $4{ }^{\circ} \mathrm{C}$. The resulting supernatant was normalized for protein content using the BCA assay kit (Thermo Fisher Scientific). Protein extracts were boiled at $96{ }^{\circ} \mathrm{C}$ for $10 \mathrm{~min}$, followed by $12 \%$ SDS-PAGE 
electrophoresis and transfer onto nitrocellulose membranes for $2 \mathrm{~h}$ at $4{ }^{\circ} \mathrm{C}$. The membranes were then blocked with $5 \%$ BSA in 0.1 M Tris-buffered saline (pH 7.4) for $1 \mathrm{~h}$ and incubated overnight in $0.5 \%$ blocking solution containing primary antibodies. After incubation with peroxidase-tagged secondary antibodies (Agilent Dako, Sta. Clara, CA, USA, 1:5000 diluted), the protein bands were developed with Luminata Forte substrate (Merck Millipore). In our experiments, nitrocellulose membranes were used to detect pSMAD1/5 (1:1000, Cat\#13820 from Cell Signaling, Beverly, MA, USA), total SMAD1/5/9 (0.625 $\mu \mathrm{g} / \mathrm{ml}$, Cat\#ab66737 from Abcam) and beta-actin (1:5000, Cat\#3700 from Cell Signaling) as loading controls.

\section{Mice}

Eight-week-old female C57BL/6J mice purchased from Envigo (formerly Harlan Laboratories; Barcelona, Spain) and provided by the Netherlands' facilities were used. The mice were housed under standard light- and climatecontrolled conditions, and standard chow and water were provided ad libitum. All experiments were performed in strict accordance with EU (Directive 2010/63/UE) and Spanish regulations (Real Decreto 53/2013; Generalitat de Catalunya Decret 214/97). The Ethics Committee on Animal Experimentation of the Vall d'Hebron Research Institute approved all procedures described in this study (protocol number: 11/13 CEEA).

\section{EAE Induction and Clinical Follow-up}

For EAE induction, anesthetized mice were immunized by subcutaneous injections of $100 \mu \mathrm{l}$ of PBS containing $200 \mu \mathrm{g}$ of peptide 35-55 from myelin oligodendrocyte glycoprotein $\left(\mathrm{MOG}_{35-55}\right.$, Proteomics Section, Universitat Pompeu Fabra, Barcelona, Spain) emulsified in $100 \mu$ l of complete Freund's adjuvant (CFA, Sigma-Aldrich) containing $4 \mathrm{mg} / \mathrm{ml}$ Mycobacterium tuberculosis H37RA (Difco Laboratories, Detroit, MI, USA). At 0 and 2 days postimmunization (dpi), the mice were intravenously injected with $250 \mathrm{ng}$ of pertussis toxin (Sigma-Aldrich). The mice were weighed and examined daily for neurological signs using the following criteria: 0 , no clinical signs; 0.5 , partial loss of tail tonus for 2 consecutive days; 1 , paralysis of the whole tail; 2 , mild paraparesis of one or both hind limbs; 2.5 , severe paraparesis or paraplegia; 3 , mild to moderate tetraparesis; 4 , tetraparesis (severe in hind limbs); 4.5 , severe tetraparesis; 5 , tetraplegia; and 6 , death [28]. A score of 5 and weight loss over $30 \%$ were defined as endpoint criteria to minimize suffering and to guarantee animal welfare. All data presented are in accordance with the guidelines suggested for EAE publications [29].

\section{In Vivo Treatment of EAE Mice}

Mice with a score of 1 or higher were randomized into the different experimental groups between 14 and 16 dpi. Once randomized, the mice were administered $3 \mathrm{mg} / \mathrm{kg} \mathrm{DM}$, $5 \mathrm{mg} / \mathrm{kg}$ DMH1, or vehicle (DMSO) intraperitoneally. The doses were selected according to the literature [30]. Mice received a final volume of $50 \mu \mathrm{l}$ every day until the end of the experiment. Clinical recovery was considered to occur when the mice had at least three consecutive days with a lower score. However, decreases from 4.5 to 4 and from 4 to 3 were not considered recovery. The mice were euthanized at 30 or $34 \mathrm{dpi}$, and immunological, histopathological, and RNA expression studies were also performed.

\section{Isolation of Immune Cells}

Spleens were removed, and the splenocytes were dissociated by grinding the spleens in a $70-\mu \mathrm{m}$ cell strainer (Cultek, Madrid, Spain). After erythrocyte removal and washing, the cells were counted for further use.

To obtain the inflammatory cells infiltrating the CNS, the spinal cords of the mice were removed at the end of the experiment, placed in a saline solution containing $1 \mathrm{mg} / \mathrm{ml}$ DNase I and $2.5 \mathrm{mg} / \mathrm{ml}$ collagenase D (both from Roche Diagnostics $\mathrm{GmbH}$, Mannheim, Germany), homogenized, and incubated at $37^{\circ} \mathrm{C}$ for $30 \mathrm{~min}$. The tissue was then ground in a $70 \mu \mathrm{m}$ cell strainer with cold $1 \mathrm{X}$ PBS and washed. The pellet was resuspended in $30 \%$ isotonic Percoll (SigmaAldrich) and was then added on top of a $70 \%$ isotonic Percoll solution. Centrifugation was carried out without braking (20 $\mathrm{min}$ at $500 \times \mathrm{g}$, at room temperature). The layer of mononuclear cells was then isolated, washed, and counted for further use.

\section{Immune Cell Activation for RNA Expression Assays}

To characterize the expression of BMP2, BMP4, BMP5, BMP6, and BMP7, the type II receptor BMPRII and the antagonist (noggin) in the immune system, spleen cell suspensions from EAE mice were prepared at different time points ( $0 \mathrm{dpi}, 7 \mathrm{dpi}, 15 \mathrm{dpi}, 30 \mathrm{dpi}$, and $49 \mathrm{dpi}$ ) of the disease. Splenocytes were seeded at a density of $2 \times$ $10^{6}$ cells/ml in IMDM medium with L-glutamine (GE Healthcare, Little Chalfont, United Kingdom) supplemented with $5 \% \mathrm{v} / \mathrm{v}$ HyClone ${ }^{\circledR}$ FetalClone I (Thermo Fisher Scientific), $40 \mathrm{U} / \mathrm{ml}$ penicillin and $40 \mathrm{mg} / \mathrm{ml}$ streptomycin (Gibco) and $60 \mu \mathrm{M} 2$ - $\beta$-mercaptoethanol (Sigma-Aldrich). Cell cultures were stimulated for $24 \mathrm{~h}$ with $50 \mathrm{ng} / \mathrm{ml}$ phorbol-12-myristate 13-acetate (PMA) and $1 \mu \mathrm{g} / \mathrm{ml}$ ionomycin (Sigma-Aldrich). 


\section{Reverse Transcription Quantitative PCR}

Total RNA from stimulated splenocytes was extracted using an RNeasy Mini kit (Qiagen, Hilden, Germany). RNA was reverse transcribed with SuperScript ${ }^{\circledR}$ VILO $^{\mathrm{TM}}$ MasterMix (Invitrogen, Carlsbad, CA, USA) and preamplified with TaqMan ${ }^{\circledR}$ PreAmp Master Mix (Thermo Fisher Scientific) when needed. Total RNA from spinal cords was extracted using TRI Reagent ${ }^{\circledR}$ (Sigma-Aldrich) and pretreated with TURBO DNase (TURBO DNA-free ${ }^{\text {TM }}$ Treatment and Removal Reagents - Ambion®, Thermo Fisher Scientific) to remove any traces of genomic DNA. Total RNA from the infiltrating inflammatory cells was extracted using the RNeasy micro kit (Qiagen) and pretreated with TURBO DNase. Next, the mRNA was reverse transcribed with SuperScript ${ }^{\circledR}$ VILO ${ }^{\mathrm{TM}}$ MasterMix (Invitrogen).

Primers for BMP2 (Mm01340178_m1), BMP4 (Mm00432087_m1), BMP5 (Mm00432091_m1), BMP6 (Mm01332882_m1), BMP7 (Mm00432102_m1), BMPRII (Mm00432134_m1), noggin (Mm01297833_s1), and housekeeping genes (glyceraldehyde 3-phosphate dehydrogenase, GAPDH (Mm99999915_g1) and hypoxanthine-guanine phosphoribosyl transferase 1, HPRT1 (Mm00446968_m1)) as well as TaqMan® Universal Master Mix II (all from Applied Biosystems, Foster City, CA, USA) were used to perform qPCR according to the manufacturer's instructions in the time course experiments. The expression of the following genes was assessed by qPCR from the total spinal cord or from infiltrating inflammatory cells obtained from vehicle- and DMH1-treated mice: GATA-3 (Mm00484683_m1), FOXP3 (Mm00475162 m1), TBX21 (Mm00450960_m1), MCR1 (Mm01329362_m1) , IL-4 (Mm00445259_m1), IL-10 (Mm01288386_m1), IFN- $\gamma$ (Mm01168134_m1), IL-17A (Mm00439618_m1), and TGF- $\beta 1$ (Mm01178820_m1). Customized ROR $\gamma \mathrm{T}$ primers and probes were described elsewhere [31].

The expression of the housekeeping gene (GAPDH or HPRT1) was used for normalization. Analysis was performed with SDS 2.4 software (Applied Biosystems). The relative level of gene expression was calculated using the $2^{-\Delta \Delta C t}$ method [32]. Before performing the statistical analysis, qPCR plate controls were checked with SDS v2.4 and RQ Manager v2.2 software (Applied Biosystems). Baseline and threshold values were manually adjusted, and any quantification cycle over 35 was considered a non-amplified sample [33]. Comparisons of mRNA expression levels in the peripheral immune system at the different time points of the experimental disease ( $7 \mathrm{dpi}, 15 \mathrm{dpi}, 30 \mathrm{dpi}$, and $49 \mathrm{dpi}$ ) referred to the basal stage $(0 \mathrm{dpi})$ in the time course experiments, and the variations in cytokine, transcription factor, and CD206 (MRC1) mRNA levels in the DMH1treated mice were compared to those of the vehicletreated group.
Splenocyte Proliferation Assay and Cytokine Profile Determination

Splenocytes were seeded in 96 -well plates at $2 \times 10^{5}$ cells $/$ well in X-VIVO ${ }^{\text {TM }} 15$ medium (Lonza) supplemented with $60 \mu \mathrm{M}$ 2-mercaptoethanol (Sigma-Aldrich), $2 \mathrm{mM} \mathrm{L-glutamine,}$ $40 \mathrm{U} / \mathrm{ml}$ penicillin and $40 \mathrm{mg} / \mathrm{ml}$ streptomycin, all obtained from Gibco. After $48 \mathrm{~h}$, the supernatants were harvested and stored at $-80{ }^{\circ} \mathrm{C}$ to further assess cytokine release. Then, $1 \mu \mathrm{Ci}$ of $\left[{ }^{3} \mathrm{H}\right]$-thymidine (PerkinElmer, Waltham, MA, USA) was added to each well, and the cultures were maintained under the same conditions for an additional $18 \mathrm{~h}$. Incorporated radioactivity was measured in a betascintillation counter (Wallac, Turku, Finland). Five replicates for each mouse and culture condition were counted, and the results were expressed as the stimulation index (SI). The SI was calculated as the quotient between the mean counts per minute $(\mathrm{cpm})$ for each stimulation condition (PHA or $\mathrm{MOG}_{35-55}$ ) and the mean cpm for the unstimulated condition.

In the in vitro studies, spleens were obtained from nonimmunized mice, and the cells were cultured under the following conditions: $10 \mu \mathrm{g} / \mathrm{ml} \mathrm{BMP} 4,1 \mu \mathrm{M}$ DM, $40 \mu \mathrm{M}$ DMH1, vehicle (DMSO and $10 \mathrm{mM}$ citric acid), $10 \mu \mathrm{g} / \mathrm{ml}$ BMP4 and $1 \mu \mathrm{M}$ DM, or $10 \mu \mathrm{g} / \mathrm{ml} \mathrm{BMP} 4$ and $40 \mu \mathrm{M}$ DMH1. In the ex vivo studies, spleens were removed from vehicle-, DM-, or DMH1-treated EAE mice at the end of the experiment, and splenocytes were cultured with $5 \mu \mathrm{g} / \mathrm{ml}$ $\mathrm{MOG}_{35-55}$ or $5 \mu \mathrm{g} / \mathrm{ml}$ phytohemagglutinin (PHA) (SigmaAldrich). The basal condition consisted of cells cultured without any stimulus in all cases.

Cytokine secretion was determined in the previously stored supernatants by Luminex technology using a ProcartaPlex Mix\&Match Mouse 12-plex to detect GM-CSF, IFN- $\gamma$, IL10, IL-12p70, IL-17A, IL-2, IL-21, IL-22, IL-23, IL-4, IL-6, and TNF- $\alpha$ (Invitrogen) according to the manufacturer's instructions.

\section{Histopathology Studies}

Mice treated with $3 \mathrm{mg} / \mathrm{kg} \mathrm{DM}, 5 \mathrm{mg} / \mathrm{kg} \mathrm{DMH} 1$, or vehicle were euthanized at the end of the experiment (day 30 or $34 \mathrm{dpi}$ ). Brains and spinal cords were removed, fixed overnight in 4\% PFA, embedded in paraffin, and cut into 4- $\mu \mathrm{m}-$ thick serial sections. Samples were stained with hematoxylin and eosin (HE) and with Klüver-Barrera (KB) to further assess the degree of inflammatory infiltration and demyelination, respectively. Cell infiltration was evaluated according to the following criteria: 0 , no lesion; 1 , cellular infiltration only in the meninges; 2 , very discrete and superficial infiltrates in the parenchyma; 3, moderate infiltrates (less than 25\%) in the white matter; 4 , severe infiltrates (less than $50 \%$ ) in the white matter; and 5, more severe infiltrates (more than 50\%) in the white matter. Demyelination was scored as follows: 0 , no 
demyelination; 1 , little demyelination, only around infiltrates and involving less than $25 \%$ of the white matter; 2 , demyelination involving less than $50 \%$ of the white matter; and 3 , diffuse and widespread demyelination involving more than $50 \%$ of the white matter. $\mathrm{HE}$ and $\mathrm{KB}$ staining was evaluated in a blinded manner.

Further immunofluorescence staining was assessed in the spinal cords of five representative mice from each experimental group to quantify astrocytosis (GFAP, Cy3conjugated mouse anti-GFAP, Cat\# C9205, SigmaAldrich), axonal damage (SMI32, mouse antinonphosphorylated neurofilaments, Cat\# 801701, Biolegend), demyelination (MBP, rabbit anti-MBP, Cat\# AB980, Millipore), activation of microglia (LEA, biotinylated lectin from Lycopersicon esculentum, Cat\# L0651, Sigma-Aldrich), and infiltration of T cells (CD3, rabbit anti-CD3, Cat\# A0452, Agilent Dako). Nonspecific protein binding was blocked with $0.2 \%$ BSA in PBS. Antigen retrieval was performed in $10 \mathrm{mM}$ citrate $(\mathrm{pH} 6)$ for CD3 and SMI32. The sections were incubated overnight at $4{ }^{\circ} \mathrm{C}$ with the primary antibodies listed above. The secondary antibodies goat-anti-rabbit Alexa 568 (Cat\# A11011, Invitrogen), goat anti-rabbit Alexa 488 (Cat\# A11034, Invitrogen), goat anti-mouse Alexa 488 (Cat\# A11029, Invitrogen) and streptavidin-FITC (Cat\# S3762, Sigma, $10 \mu \mathrm{g} / \mathrm{ml}$ ) were incubated for $1 \mathrm{~h}$ at room temperature. Nuclei were counterstained with DAPI (Cat\# D9542, Sigma). Cell counts of the inflammatory infiltrates in the white matter were evaluated in 3 areas $\left(0.25 \mathrm{~mm}^{2}\right)$ along the spinal cord for each mouse. The percentage of positively stained cells was obtained in each area for CD3, whereas the percentage of positively stained area was assessed for SMI32, GFAP, LEA, and MBP.

$\mathrm{HE}$ and $\mathrm{KB}$ staining, as well as all immunostaining, was read and evaluated in a blinded manner.

\section{Flow Cytometry}

Freshly isolated splenocytes were labelled with an appropriate combination of the following antibodies: B220FITC (Cat\# 553088, BD Biosciences, New Jersey, USA), CD1d-PE (Cat\# 553846, BD), CD3e-FITC (Cat\# 561827, BD), CD4-PerCP (Cat\# 5611090, BD), CD5APC (Cat\# 550035, BD), CD8a-APCeFluor780 (Cat\# 47-0081, eBioscience, Thermo Fisher Scientific), CD11b-APC (Cat\# 17-0112, eBioscience, Thermo Fisher Scientific), CD11b-BV421 (Cat\# 562805, BD), CD11c-PE (Cat\# 553502, BD), CD25-PE (Cat\# 12-0251, eBiosciences, Thermo Fisher Scientific), CD206-AF647 (Cat\# 141712, BioLegend, San Diego, CA, USA), CD317-APC (Cat\# 17-3172, eBiosciences, Thermo Fisher Scientific), F4/80-PE (Cat\# 565410, BD), FoxP3APC (Cat\# 17-5773, eBiosciences, Thermo Fisher
Scientific), Ly6C-PE/Cy7 (Cat\# 560593, BD), and Ly6G-FITC (Cat\# 551460, BD). Fc receptors were blocked with rat anti-mouse CD16/32 (Cat\# 553142, BD). Dead cells were stained with Fixable Viability Dye eFluor450 (eBiosciences, Thermo Fisher Scientific) or Fixable Viability Stain 510 (BD). Samples were acquired in a Cytoflex flow cytometer (Beckman Coulter, Brea, CA, USA) and analyzed with CytExpert 2.0 software (Beckman Coulter).

Analysis of the studied cell populations was performed as follows: the population of interest (total cells for the myeloid subsets or lymphocytes for $\mathrm{T}$ and $\mathrm{B}$ cells) was selected by means of forward (FSC-H) and side scatter (SSC-H). Then, FSC-A and FSC-H were combined to discriminate doublets, and viability dye was used to rule out dead cells from the analysis. We determined the frequency in the periphery of total B cells (B220+ events), Tindependent $\mathrm{B}$ cells (B1: $\mathrm{B} 220^{+} \mathrm{CD}^{+}$events), $\mathrm{T}$ dependent $\mathrm{B}$ cells (B2: $\mathrm{B} 220^{+} \mathrm{CD} 5^{-}$events), B regulatory cells $\left(\mathrm{CD} 1 \mathrm{~d}^{\text {high }} \mathrm{CD}^{+}\right.$events in the $\mathrm{B} 220^{+}$population), CD4 $\mathrm{T}$ cells $\left(\mathrm{CD} 3 \mathrm{e}^{+} \mathrm{CD} 4^{+}\right.$events), CD8 T cells $\left(\mathrm{CD} 3 \mathrm{e}^{+} \mathrm{CD} 4^{-}\right.$events), CD4 regulatory $\mathrm{T}$ cells (Tregs; $\mathrm{CD} 25^{+} \mathrm{FoxP}_{3}{ }^{+}$events in the $\mathrm{CD} 3 \mathrm{e}^{+} \mathrm{CD} 4^{+}$population), myeloid cells (CD11 bigh events), macrophages $\left(\mathrm{CD} 11 \mathrm{~b}^{+} \mathrm{F} 4 /\right.$ $80^{+}$events), neutrophils ( $\mathrm{Ly}_{6 \mathrm{G}}{ }^{+} \mathrm{F} 4 / 80^{-}$events in the $\mathrm{CD} 11 \mathrm{~b}^{+}$population), monocytic-myeloid-derived suppressor cells (M-MDSCs; Ly6 $\mathrm{G}^{-}$Ly6 $6 \mathrm{C}^{\text {high }}$ events in the $\mathrm{CD} 11 \mathrm{~b}^{+}$population), M2 macrophages $\left(\mathrm{Ly} 6 \mathrm{C}^{-} \mathrm{CD} 206^{+}\right.$ events in the $\mathrm{Ly} 6 \mathrm{G}^{-} \mathrm{CD} 11 \mathrm{~b}^{+} \mathrm{F} 4 / 80^{+}$population), lymphoid DCs $\left(\mathrm{CD} 11 \mathrm{c}^{\text {high }} \mathrm{CD} 8 \mathrm{a}^{+}\right.$events in the $\mathrm{B} 220^{-} \mathrm{CD} 11 \mathrm{~b}^{+}$population), myeloid DCs $\left(C D 11 \mathrm{c}^{\text {high }} \mathrm{CD} 8 \mathrm{a}^{-}\right.$events in the $\mathrm{B} 220^{-} \mathrm{CD} 11 \mathrm{~b}^{+}$population), and plasmacytoid DCs $\left(\mathrm{CD} 11 \mathrm{c}^{\text {int }} \mathrm{CD} 317^{+}\right.$events in the $\mathrm{B} 220^{+} \mathrm{CD} 11 \mathrm{~b}^{-}$population). Nuclear FoxP3 staining was performed with the FoxP3 staining set (eBiosciences, Thermo Fisher Scientific). Intracellular staining of CD206 was performed using the Cytofix/Cytoperm kit (BD).

\section{Statistical Analysis}

The data are expressed as the mean \pm standard deviation (SD) unless otherwise stated. We used Student's $t$ test to compare variables from two independent groups with $\mathrm{R}$ software (R version 3.2.0, Copyright $\odot 2015$ The R Foundation for Statistical Computing) and SPSS Statistics v20 (IBM Corp.). When needed, SAS@ 9.4 (SAS Institute Inc., Cary, NC, USA) was used to compare groups using mixed models to account for clustering by experiment and/or repeated measures. Statistical significance in the case of multiple comparisons with a common group was managed with Dunnett's adjustment. The level of statistical significance was set at 0.05 . Graphics were generated with GraphPad Prism v5.0. 


\section{Results}

\section{In Vitro Studies}

\section{BMP4 Favors Splenocyte Proliferation In Vitro}

Jurkat cells were cultured in the presence of BMP4 or BMP4 in combination with noggin, DM, or DMH1. We were able to detect the phosphorylated form of SMAD1/5 and verified the capacity of the two small molecules to inhibit signaling through the cytoplasmic mediator of the canonical BMP signaling pathway in a way similar to noggin, which is one of the physiological antagonists of BMPs (Fig. 1a). Once we verified that BMP4 was able to signal in immune cells and that DM and DMH1 were capable of inhibiting BMP signaling, we then sought to elucidate whether BMP4 had an effect on the proliferation and cytokine release pattern of splenocytes. Splenocytes from naïve mice were isolated and cultured in the presence of BMP4 alone or combined with DM or DMH1. We performed three independent experiments and included two or three replicates per condition in each experiment, in which we used splenocytes from different mice. The SI was calculated as the mean cpm for each experimental condition with respect to the mean cpm in the basal condition. Proliferation was induced in cultures to which BMP4 was added (SI $6.28 \pm 1.05$ ), while it was inhibited in splenocytes cultured with BMP4 in combination with DM (SI $1.14 \pm 0.80$ ) or DMH1 (SI 1.13 \pm 0.71 ), indicating that the canonical signaling pathway mediated the proliferation of the immune cells (Fig. 1b). In addition, the proliferative capacity of immune cells was not altered when splenocytes were cultured in the presence of DMSO and $10 \mathrm{mM}$ citric acid (vehicle control, SI $1.03 \pm 0.28$ ).

\section{BMP4 Induces the Secretion of Pro-inflammatory Cytokines}

Next, we analyzed the cytokine release pattern in the supernatants of splenocytes. The levels of pro-inflammatory cytokines increased in the presence of BMP4 (GM-CSF: 18.51 \pm $6.14 \mathrm{pg} / \mathrm{ml} ;$ IFN- $\gamma: 209.02 \pm 178.31 \mathrm{pg} / \mathrm{ml} ;$ IL-6: $522.04 \pm$ $163.57 \mathrm{pg} / \mathrm{ml}$; TNF- $\alpha$ : $326.30 \pm 73.20 \mathrm{pg} / \mathrm{ml})$, and DMH1 showed the strongest capacity to inhibit their expression

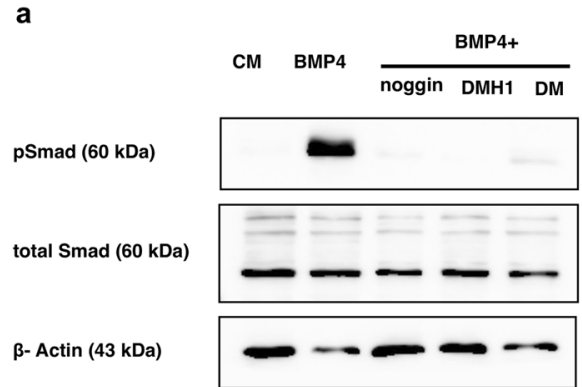

b

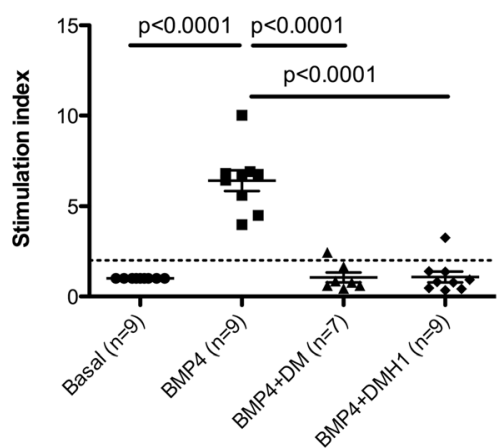

Fig. 1 BMP4 favours in vitro proliferation and pro-inflammatory cytokine production. (a) pSMAD1/5 was detected by western blot in Jurkat cells cultured in the presence of BMP4 $(500 \mathrm{ng} / \mathrm{ml})$ for $30 \mathrm{~min}$; the phosphorylated form of the protein decreased or disappeared when noggin, DM or DMH1 was added to the culture medium in the presence of BMP4. (b) Splenocytes from naïve mice were cultured in the presence of BMP4 $(10 \mu \mathrm{g} / \mathrm{ml})$ or a combination of BMP4 and DM $(1 \mu \mathrm{M})$ or DMH1 $(40 \mu \mathrm{M})$. BMP4 induced splenocyte proliferation, while proliferation was abrogated in the presence of DM and DMH1, which are BMP signaling inhibitors. The dotted line represents the proliferation threshold. Data
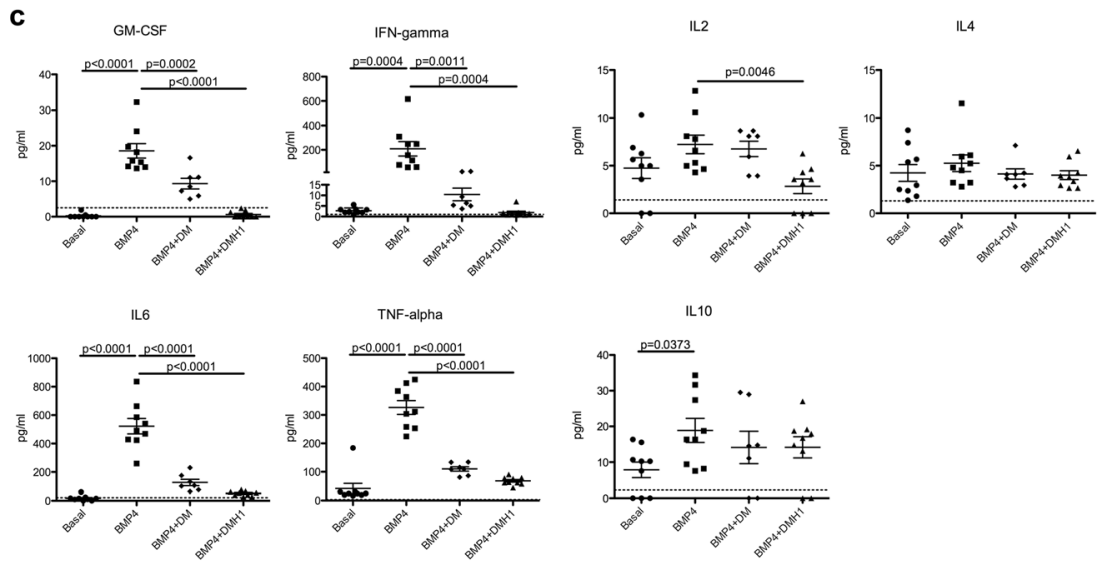

TNF-alpha

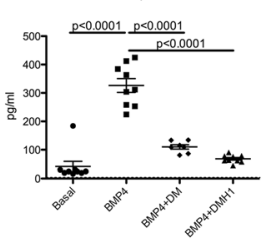

IL10

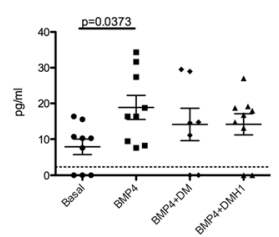

1122
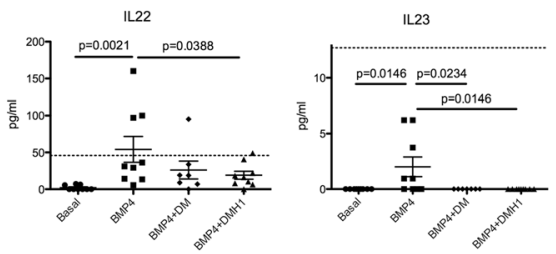

correspond to three independent experiments. (c) Cytokines were quantified in the supernatants of splenocytes cultured with BMP4, BMP4+ $\mathrm{DM}$, or BMP4+DMH1. The dotted line indicates the lower limit of quantification for each cytokine. Data are represented as the mean \pm standard error of the mean (SEM). Data were analyzed with mixed models to account for clustering by experiment and repeated measures. All conditions were compared with the BMP4-treated cultures using Dunnett's adjustment. BMP4 = bone morphogenetic protein $4 ; \mathrm{CM}=$ culture medium; DM = dorsomorphin; DMH1 = dorsomorphin homologue 1 
(GM-CSF: $0.61 \pm 0.96 \mathrm{pg} / \mathrm{ml}, p<0.0001 ;$ IFN- $\gamma: 1.90 \pm$ $1.98 \mathrm{pg} / \mathrm{ml}, p=0.0004$; IL-6: $50.12 \pm 17.31 \mathrm{pg} / \mathrm{ml}$, $p<0.0001$; TNF- $\alpha$ : $68.07 \pm 13.93$ pg/ml, $p<0.0001$; Fig. 1c). In addition, BMP4 increased the secretion of IL-10, but it had no effect on the secretion of IL-2 or IL-4 (Fig. 1c). Moreover, we observed significantly reduced production of IL-2 when BMP4 was combined with DMH1 (Fig. 1c). In contrast, IL-12p70 was hardly detected in any of the tested conditions, although a slight but significant increase in this cytokine was observed in the supernatant of splenocytes cultured in the presence of BMP4 (basal $0.45 \pm 0.79$ vs BMP4 $1.29 \pm 0.77, p=0.0043)$. Concerning Th17 cytokines, we were not able to detect IL-17A in any of the studied conditions, but we could detect increased release of IL-22 (basal: $2.14 \pm 3.24 v s$ BMP4: $54.11 \pm 52.57, p=0.0021)$ and IL-23 (basal: no detection vs BMP4: $2.01 \pm 2.66, p=0.0146$ ) from splenocytes cultured with BMP4, although most of the samples were under the lower level of quantification of the kit. Moreover, BMP signaling inhibitors significantly reduced the levels of the mentioned cytokines (Fig. 1c).

Altogether, these results suggest that BMP4 may be involved in the positive regulation of pro-inflammatory immune responses.

\section{In Vivo Studies I: Pattern of Expression of BMPs in an Animal Model of MS}

To investigate the involvement of BMPs in the immune response in the context of MS, we aimed to elucidate the relevance of the BMP signaling pathway in the immune system in a murine model of MS by studying the changes in the expression of BMPs (BMP2, BMP4, BMP5, BMP6, and BMP7), BMP type II receptor (BMPRII), and the physiological antagonist noggin in the immune system in four different phases of EAE development.

\section{EAE Model}

EAE is the most common animal model of MS, as it shares clinical, histopathological, and pathogenic features with the human disease. We chose the chronic MOG-based EAE model for our experiments since its chronic clinical course resembles most of the histopathology of MS, presenting several inflammatory infiltrates and extensive demyelination.

The incidence in our animal model was $100 \%$, and no animals died. The diseased mice presented constant and progressive myelopathy, first affecting tail and hind limb mobility and later reaching the forelimbs. Disease onset occurred at $12.60 \pm 2.10 \mathrm{dpi}$, and the highest mean clinical score was reached at 19 dpi. From 19 dpi until the end of the experiment, the mice presented a clinical score of $4.00 \pm 0.00$. Six to eight animals were euthanized at each time point: before EAE induction (baseline (0 dpi)), at induction (before onset, $7 \mathrm{dpi}$ ), and in the inflammatory (peak of disease, $15 \mathrm{dpi}$ ), early chronic (30 dpi) and late chronic (49 dpi) phases of the experimental disease (Fig. 2a).

\section{Expression of BMP2, BMP4, BMP5, BMP6, BMP7, BMPRII, and Noggin at Different Time Points in the Chronic EAE Model}

To characterize BMPs, BMPRII, and noggin expression profiles during the time course of the experimental disease, splenocytes from EAE mice were stimulated ex vivo with PMA and ionomycin for $24 \mathrm{~h}$, and mRNA expression levels were evaluated by qPCR.

Both basal and EAE cultured splenocytes showed expression of BMP2, BMP4, BMP6, BMP7, BMPRII, and noggin. However, no BMP5 expression was detected. While no differences were observed regarding BMP4 expression in any of the studied phases (Fig. 2c), BMP2, BMP7, BMPRII, and noggin showed a peak of expression in the induction phase that was maintained in the inflammatory phase (Fig. 2b, e-g). BMP2, BMP7, BMPRII, and noggin showed a similar expression pattern, but mRNA expression levels were quite different between these analyzed proteins. The highest increase was observed in noggin expression (Fig. 2g), for which expression levels were 21 -fold $(p<0.01)$ and 14 -fold $(p<0.001)$ over the baseline in the induction and inflammatory phases, respectively. Quantification of BMP2 mRNA from ex vivo-stimulated splenocytes showed the second most pronounced increase (Fig. 2b). BMP2 mRNA levels reached almost 7 -fold $(p<0.001)$ and 3-fold $(p<0.001)$ higher expression in the induction and inflammatory phases, respectively. Regarding BMP7 and BMPRII, not only were their expression patterns similar but their expression levels were also increased by 2 -fold and 1.5 -fold in the induction and inflammatory phases, respectively (Fig. 2e, f). Conversely, BMP6 showed the opposite behavior of the other BMPs and was downregulated once EAE was induced. Thus, BMP6 expression was almost 10-fold lower $(p<0.001)$ in the induction phase than in the basal condition (Fig. 2d). Moreover, BMP6 mRNA expression was lost in almost all samples in the induction phase and was not detected in all samples at the remaining time points, thus indicating a loss of BMP6 expression in peripheral immune cells in EAE.

In the chronic stages of the experimental disease (30 dpi, early chronic phase, and $49 \mathrm{dpi}$, late chronic phase), the increased expression of BMP2, BMP7, BMPRII, and noggin was maintained (Fig. 2b, e-g). In addition, BMP6 mRNA expression was abrogated in the majority of mice upon EAE induction: BMP6 was detected in only two mice in the induction phase, 4 mice in the inflammatory phase, and 5 mice in the early and late chronic phases. In this respect, the 
a

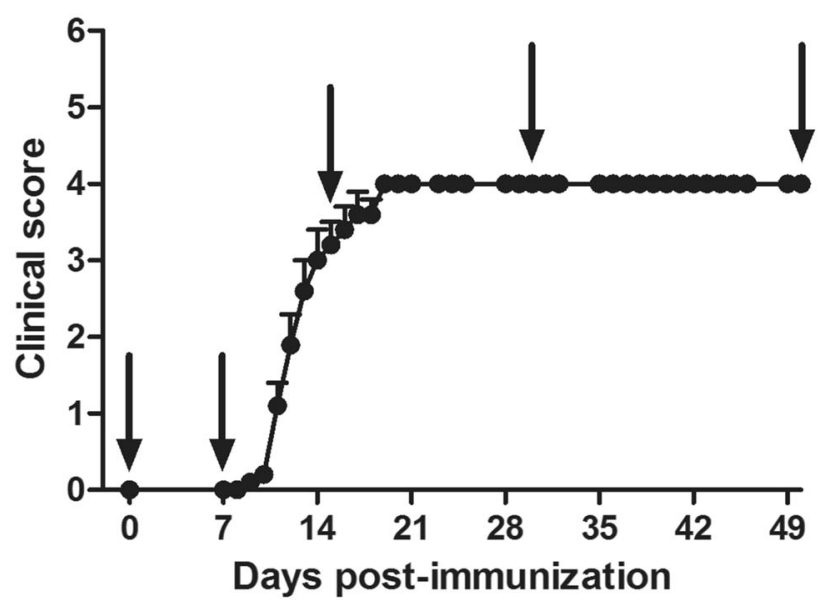

b
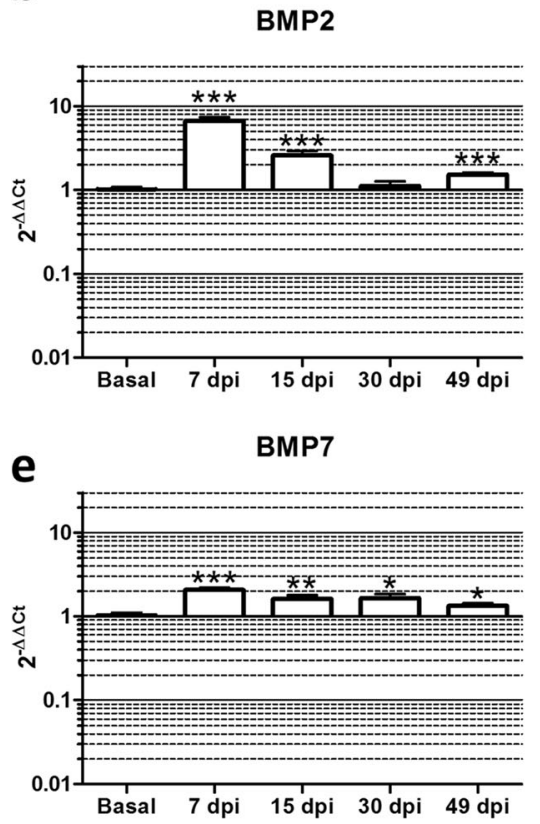

C

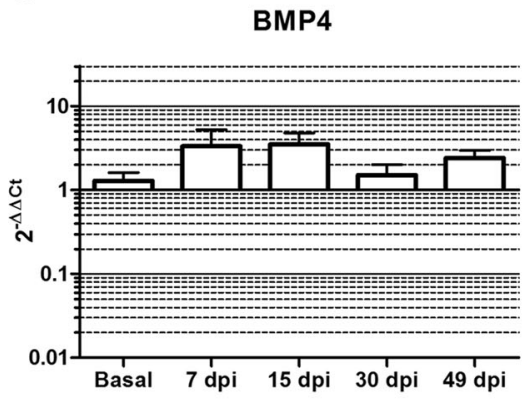

f

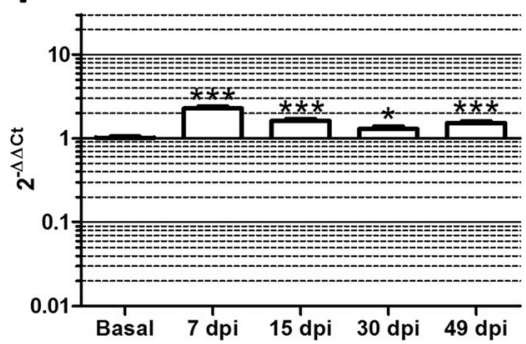

d

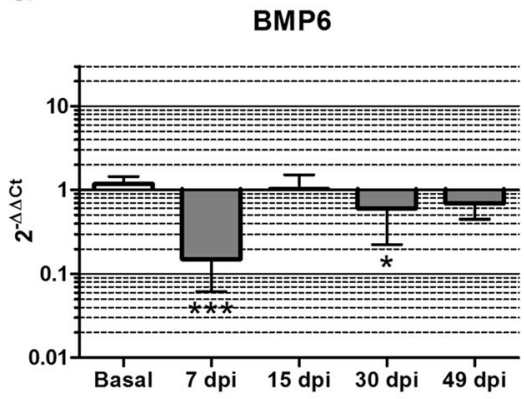

g

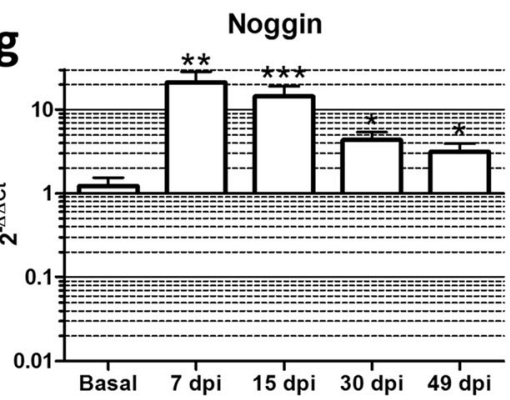

Fig. 2 BMPs, BMPRII, and the antagonist noggin are differentially expressed in the peripheral immune system in EAE mice. (a) The expression of BMPs, the receptor BMPRII, and the antagonist noggin was analyzed in the peripheral immune system at different time points: at baseline (basal), during induction (7 dpi), and in the inflammatory (15 dpi), early chronic (30 dpi), and late chronic (49 dpi) phases of

expression of BMP6 was 1.6-fold $(p<0.05)$ lower in the early chronic phase and almost 1.5 -fold lower in the late chronic phase (Fig. 2d) than at baseline.

Our results indicate that the major alterations in the expression of BMPs and noggin take place in the initial and inflammatory phases of EAE, suggesting a role in the initial stages of the immune response.
EAE. Expression levels were evaluated by qPCR for (b) BMP2, (c) BMP4, (d) BMP6, (e) BMP7, (f) BMPRII, and (g) noggin in splenocytes stimulated in vitro. Six to eight mice were analyzed at each time point. For statistical analysis, Student's $t$ test was used to compare $\Delta \Delta \mathrm{Ct}$ (each studied phase $v s$ the baseline). Data represent the mean \pm standard error of the mean (SEM). * $p<0.05 ; * * p<0.01 ; * * * p<0.001$

\section{In Vivo Studies II: Inhibition of the BMP Signaling Pathway with Small Molecules as a Therapeutic Approach for MS}

To test whether inhibition of the BMP signaling pathway could be an effective therapy for MS, we tested DM and DMH1 small molecules to therapeutically treat EAE- 
diseased mice, and we then further studied whether inhibition of the BMP signaling pathway induces changes in the immune response.

\section{In Vivo Blockade of BMP Signaling Reduces EAE Severity and CNS Damage}

EAE was induced in female C57BL6/J mice. The mice were randomized when the first clinical symptoms appeared (clinical score $\geq 1$ ) in equivalent groups in terms of accumulated score, onset day, days of disease and total accumulated score (Table 1). Then, mice were treated daily with $3 \mathrm{mg} / \mathrm{ml} \mathrm{DM}$, $5 \mathrm{mg} / \mathrm{ml} \mathrm{DMH1}$ or DMSO (vehicle group) in a final volume of $50 \mu \mathrm{l}$ via intraperitoneal injection. Two independent experiments were performed.

Mice treated with DM and DMH1 presented a reduction in the severity of the disease (Fig. 3a). Indeed, the area under the curve (AUC) of the clinical course tended to be reduced in both the DM-treated group and the DMH1-treated group (Fig. $3 b)$. Furthermore, the accumulated score was reduced in both treated groups compared to the vehicle-treated group (vehicle group: $67.42 \pm 14.78$; DM group: $55.96 \pm 19.77$; DMH1 group: $54.12 \pm 18.76 ; p=0.0685$ and $p=0.0566$, respectively). In addition, there was a tendency toward a decrease in the maximum score in the $\mathrm{DM}(3.81 \pm 0.83, p=0.1026)$ and DMH1 groups $(3.85 \pm 0.66, p=0.0874)$ compared to the vehicle group $(4.31 \pm 0.66)$.

A histopathology study was carried out to determine the degree of inflammation and demyelination after DM and DMH1 treatment. Globally, the spinal cords of DM and DMH1-treated mice presented lower inflammation and demyelination, although statistical significance was not reached (Fig. 4a). We performed a more detailed histopathology study on samples from five representative mice in the vehicle group and five DM- or DMH1-treated mice that experienced a clinical recovery; consequently, the mean AUC of the clinical score was lower in the DM- $(36.65 \pm 15.70 ; p=0.0593)$ and DMH1-treated mice $(34.40 \pm 15.02 ; p=0.0065)$ than in the vehicle-treated mice $(65.40 \pm 9.67)$ included in the histopathology study. Moreover, the AUC and the score at the end of the experiment are represented in Fig. $4 \mathrm{~b}$. Recovered mice presented less infiltration of $\mathrm{T}$ cells, less astrogliosis, fewer reactive microglia, and less demyelination than vehicle-treated mice (Fig. 4c). Indeed, axonal damage was also reduced, but the differences did not reach statistical significance (Fig. 4c).

Our data show that blockade of the BMP signaling pathway with small molecules improves EAE clinical outcomes and ameliorates the CNS damage caused by the inflammatory process that induces EAE.

\section{Study of Peripheral Immune Function in DMH1- Treated Mice}

Although DM was the first BMP-specific inhibitor identified, it shows off-target effects, including inhibition of AMPK and VEGF signaling [34]. In subsequent studies, DMH1 was identified as a highly selective inhibitor of BMP signaling that does not disturb other signaling pathways [27]. Moreover, both inhibitors showed similar effects in our experiments. Consequently, we decided to analyze the immune response in DMH1-treated mice.

To this end, we first determined whether the proliferative capacity of splenocytes from DMH1-treated mice was altered, but we observed no differences in terms of the proliferation of splenocytes challenged with $\mathrm{MOG}_{35-55}$ or PHA (data not shown). In addition, the profile of $\mathrm{Th} 1 / \mathrm{Th} 2 / \mathrm{Th} 17 /$ regulatory cytokine release was similar in the supernatants of $\mathrm{MOG}_{35-55^{-}}$ challenged splenocytes from mice in both experimental groups (data not shown), indicating that BMP signaling blockade did not affect the immune response in vivo.

Table 1 Clinical parameters of the randomized groups

\begin{tabular}{|c|c|c|c|c|c|}
\hline & & Accumulated score* & Onset day* & Days of disease* & Accumulated score (total) \\
\hline \multirow[t]{3}{*}{ Vehicle } & $1(n=6)$ & $10.58 \pm 6.45$ & $12.00 \pm 1.55$ & $4.00 \pm 1.55$ & 63.50 \\
\hline & $2(n=7)$ & $8.70 \pm 4.55$ & $11.00 \pm 1.22$ & $3.00 \pm 1.22$ & 43.50 \\
\hline & & $14.50 \pm 6.36$ & $11.00 \pm 1.41$ & $5.00 \pm 1.41$ & 29.00 \\
\hline \multirow[t]{3}{*}{$\mathrm{DM}$} & $1(n=6)$ & $10.92 \pm 6.21$ & $12.00 \pm 0.89$ & $4.00 \pm 0.89$ & 65.50 \\
\hline & $2(n=7)$ & $8.70 \pm 4.55$ & $11.00 \pm 1.22$ & $3.00 \pm 1.22$ & 43.50 \\
\hline & & $18.00 \pm 1.41$ & $11.00 \pm 1.41$ & $5.00 \pm 1.41$ & 36.00 \\
\hline \multirow[t]{3}{*}{ DMH1 } & $1(n=6)$ & $10.92 \pm 7.00$ & $12.00 \pm 1.55$ & $4.00 \pm 1.55$ & 65.50 \\
\hline & $2(n=7)$ & $8.70 \pm 4.55$ & $11.00 \pm 1.22$ & $3.00 \pm 1.22$ & 43.50 \\
\hline & & $16.25 \pm 4.60$ & $10.50 \pm 0.71$ & $5.50 \pm 0.71$ & 32.50 \\
\hline
\end{tabular}

Data from two independent experiments are shown. In the second experiment, the mice are randomized in two rounds

*Data are expressed as the mean \pm standard deviation. DM $=$ dorsomorphin, DMH1 = dorsomorphin homologue 1 


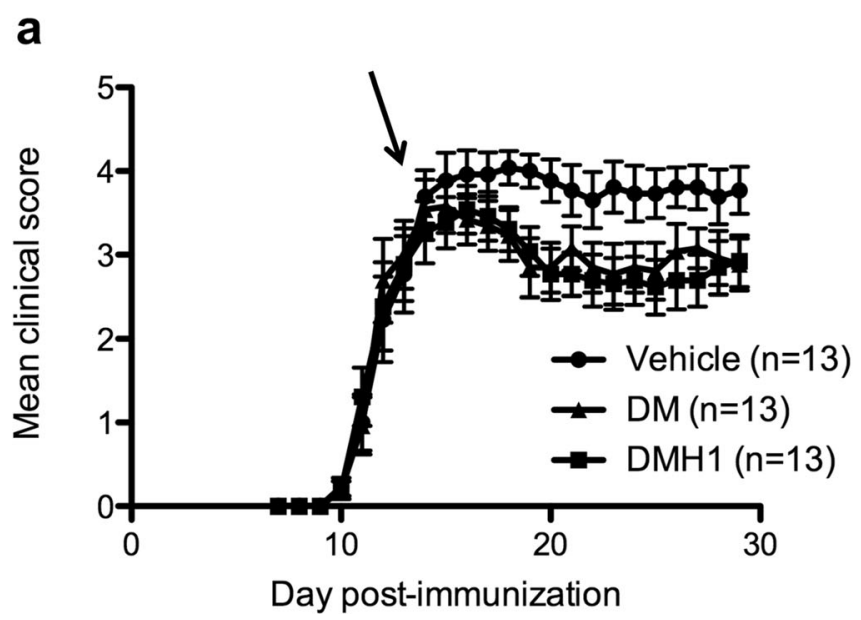

Fig. 3 Inhibition of BMP signaling improves EAE clinical outcomes. (a) EAE mice were randomized when the first clinical symptoms appeared (clinical score $\geq 1$ ) and treated daily with $3 \mathrm{mg} / \mathrm{kg} \mathrm{DM}, 5 \mathrm{mg} / \mathrm{kg}$ DMH1, or DMSO (vehicle). (b) EAE clinical outcomes improved in mice treated with the BMP signaling inhibitors, and the area under the curve tended to decrease in DMH1-treated mice. Data compile two independent

We then analyzed the frequency of T- and B-cell subsets and myeloid cells in the peripheral immune system by flow cytometry. We found differences in neither T- and B-cell subsets nor the frequency of MDSCs and neutrophils (data not shown), but we detected a decrease in the whole population of CD11 bigh cells and a moderate reduction in macrophages (Fig. $5 \mathrm{a}$, d). In a second experiment, we studied myeloid subsets in more detail. Interestingly, DMH1-treated mice presented an increased frequency of plasmacytoid dendritic cells (pDCs), but in contrast, the M2 population was reduced (Fig. 5b-d), although the ratio of pro- and anti-inflammatory macrophages did not significantly change (data not shown).

\section{Study of the CNS Immune Response in DMH1-Treated Mice}

We finally determined the expression of Th1 (TBX21), Th2 (GATA3), Th17 (ROR $\gamma \mathrm{T}$ ), and Treg (FOXP3) transcription factors and of M2 macrophage markers (MRC1 or CD206) in the whole spinal cord and the inflammatory infiltrate.

Gene expression was similar in whole spinal cords of vehicle- and DMH1-treated mice (Fig. 6a). Accordingly, no differences were found when comparing the expression levels of transcription factors in the inflammatory infiltrate, although MRC1 tended to be downregulated in DMH1-treated mice compared to vehicle-treated mice (Fig. 6b).

Altogether, these results suggest that blockade of the BMP signaling pathway with small molecules minimally disturbs the peripheral and CNS immune systems in EAE mice.

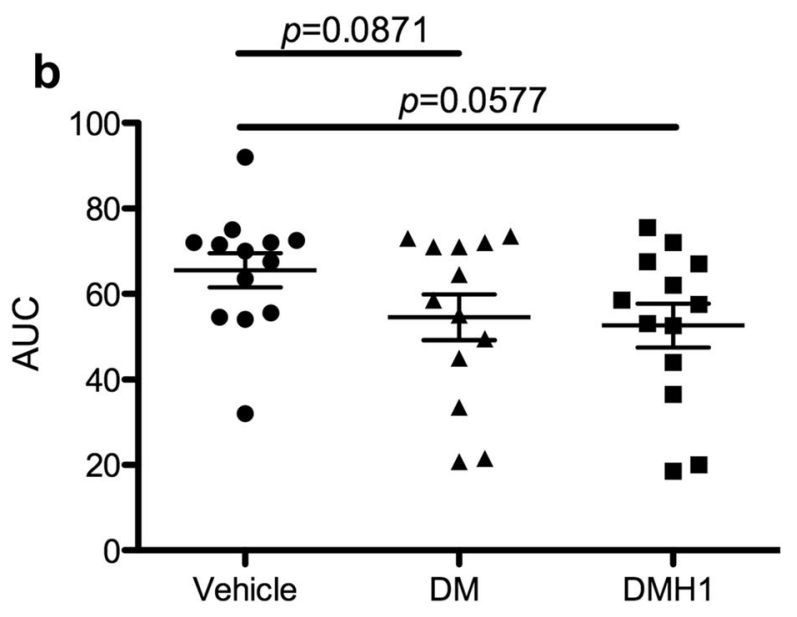

experiments and are presented as the mean \pm standard error of the mean (SEM). The statistical analysis was performed with mixed models to account for clustering by experiment. AUC = area under the curve; DM $=$ dorsomorphin; $\mathrm{DMH} 1$ = dorsomorphin homologue 1 . The arrow indicates the start of treatment

\section{Discussion}

BMPs are a subgroup of signaling ligands in the transforming growth factor beta (TGF- $\beta$ ) superfamily. They are involved not only in development but also in the preservation of stem cell niches, in cell lineage fate, and in the survival and proliferation of various cell types. In the immune system, BMPs are involved in the maintenance of the hematopoietic stem cell niche [35] and in the development of various immune cell lineages $[13,36]$. For instance, immune cells are capable of responding to BMPs, as shown by phosphorylation of the cytoplasmic mediator Smad1/5/8 [14, 15]. We confirmed these findings since splenocytes from naïve mice presented a stronger capacity to proliferate when cultured in the presence of BMP4; therefore, BMP4 induced significant production and release of pro-inflammatory cytokines and IL-10 but did not alter the production of IL-4. In addition, when the canonical signaling pathway of BMP4 was abrogated using small molecules, splenocytes did not proliferate and produced lower levels of pro-inflammatory cytokines, indicating that BMP4 activated splenocytes specifically through phosphorylation of the cytoplasmic mediator Smad1/5/8. In contrast, inhibiting the phosphorylation of Smad1/5/8 did not reduce the production of IL-10 in murine splenocytes, suggesting that BMP4 may regulate the production of pro-inflammatory and regulatory cytokines via different signaling pathways. Consistent with this line of evidence, BMP4 has been reported to act as a negative regulator of the adaptive immune response by impairing the maturation of DCs via non-canonical signaling pathways [18], while it supports human DC maturation and differentiation through the canonical signaling pathway [19]. BMPs have also been proposed to control the differentiation 


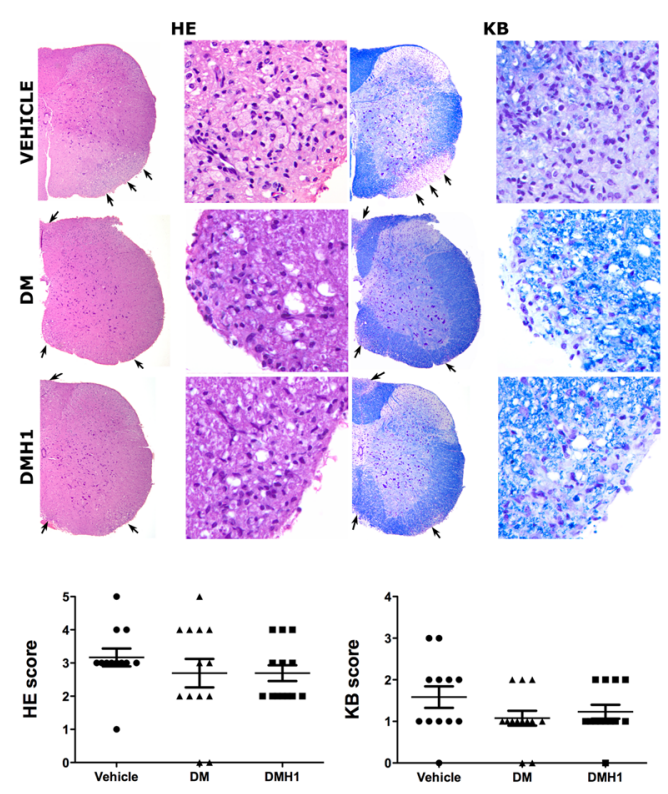

b

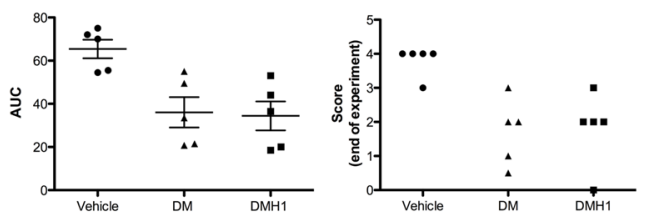

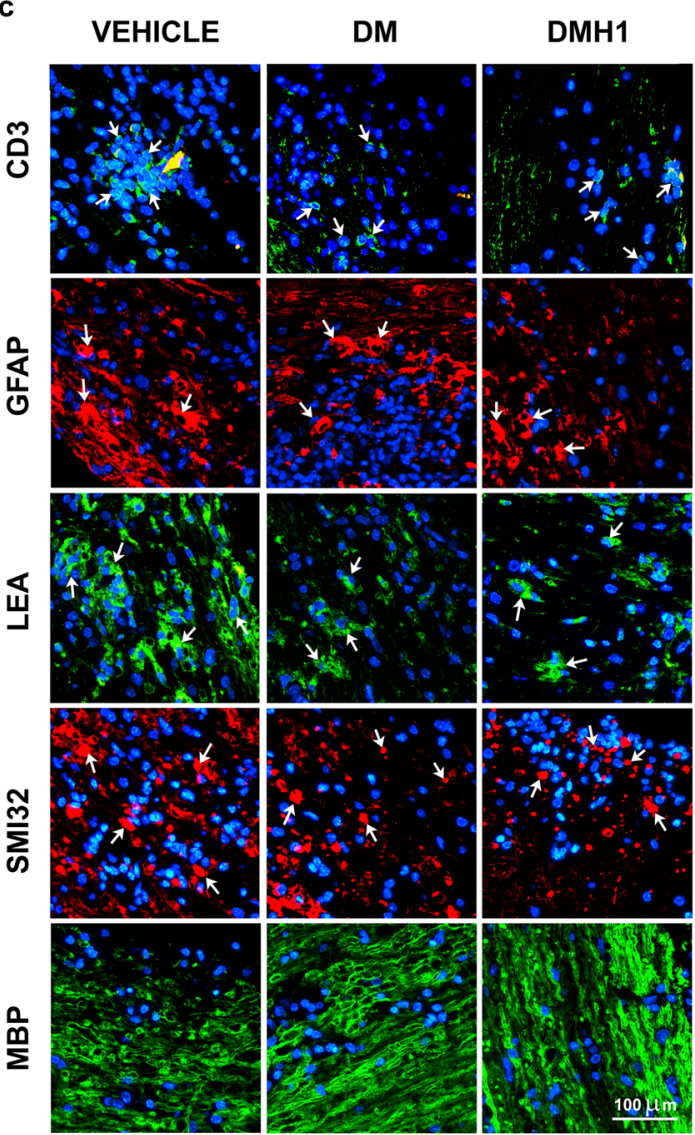
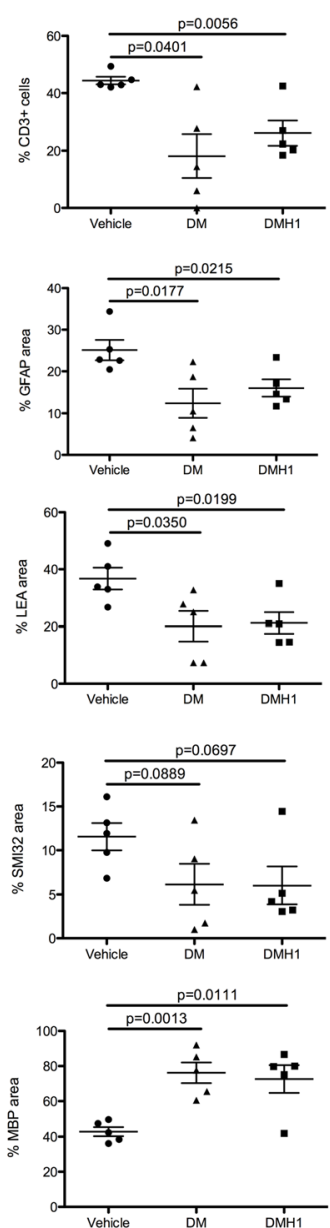

Fig. 4 BMP signaling blockade decreases CNS damage in EAE mice. (a) The degree of inflammatory infiltration (left panel and graph) and demyelination (right panel and graph) was assessed by hematoxylin and eosin and Klüver-Barrera staining in the spinal cords of vehicle-, DM- and DMH1-treated mice. (b) A more detailed histopathological study was performed on the spinal cords of five representative mice from the vehicle group and five DM- or DMH1-treated mice that experienced clinical recovery. The graphs show the area under the curve and the score at the end of the experiment for the selected mice. (c) Demyelination (MBP), axonal damage
(SMI32), astrogliosis (GFAP), microglial activation (LEA), and T-cell infiltration (CD3) were assessed via immunofluorescence. Data are presented as the mean \pm standard error of the mean (SEM). Arrows indicate positive staining for each marker. The statistical analysis was performed with mixed models to account for clustering by experiment. $\mathrm{AUC}=$ area under the curve; $\mathrm{DM}=$ dorsomorphin; DMH1 = dorsomorphin homologue 1; GFAP = glial fibrillary acidic protein; $\mathrm{HE}=$ hematoxylin and eosin; $\mathrm{KB}=$ Klüver-barrera; $\mathrm{LEA}=$ lectin from Lycopersicon esculentum; $\mathrm{MBP}=$ myelin basic protein

to limit excessive exposure of cells to BMPs [37]. Similarly, the expression of BMPs in the immune system could induce strong and rapid upregulation of noggin to avoid an excessive immune response. It is in the induction phase and in the inflammatory phase of EAE to a lesser extent that BMPs change their expression more notably, which suggests that they can play a role in modulation of the immune response. BMP2 and BMP7 increased in the first stages of EAE; however, their multiple functions and targets in the immune system (Fig. 7) make it difficult to determine whether they may play a detrimental or beneficial role in the regulation of the immune response. Our in vitro studies revealed that BMP4 promoted proliferation and a pro-inflammatory profile in murine immune cells. Considering that BMP2 is structurally and functionally related to BMP4 [38], the significant increase in the 


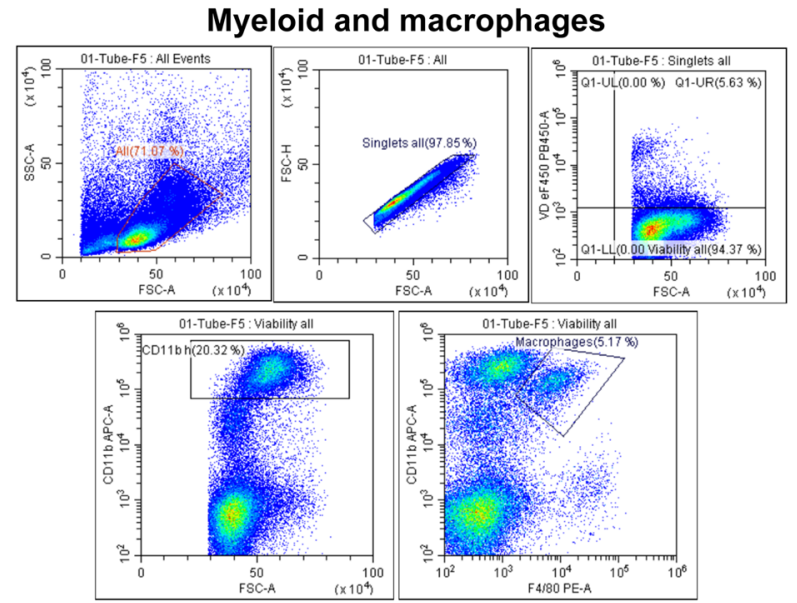

c

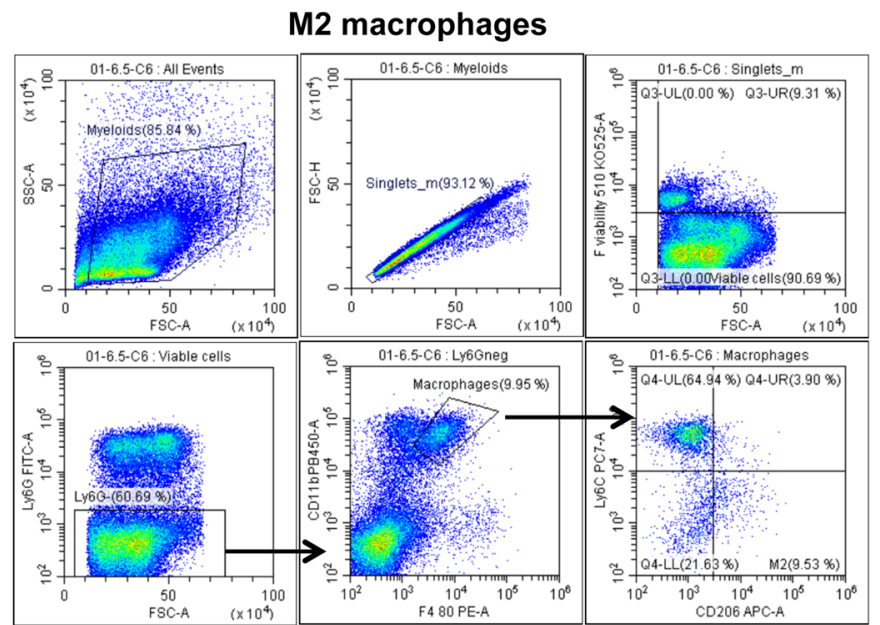

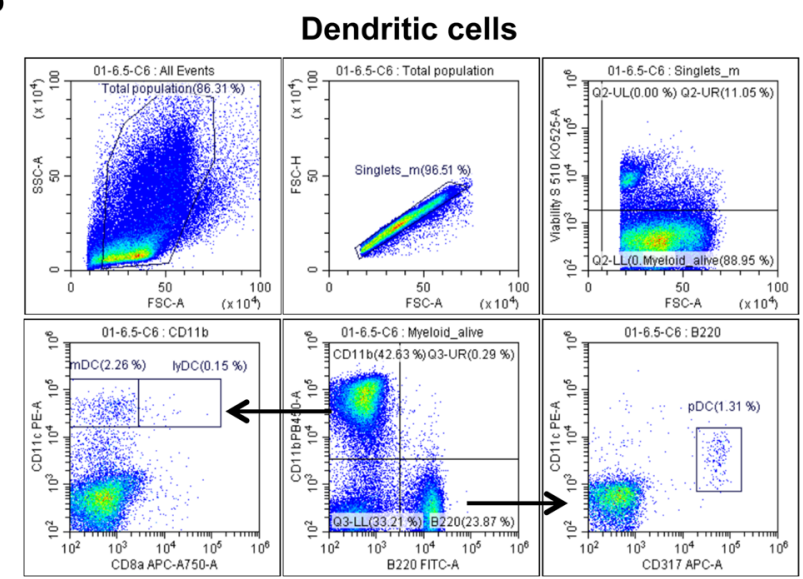

d
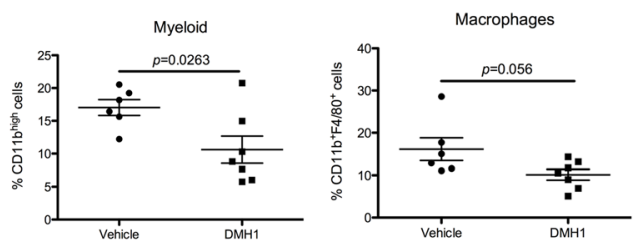

Lymphoid DC

Myeloyd DC
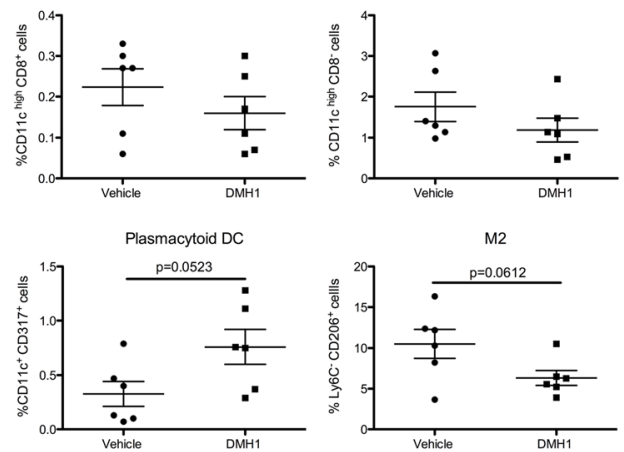

Fig. 5 BMP signaling blockade changes the frequencies of myeloid subsets in the peripheral immune system. Freshly isolated splenocytes were stained for flow cytometry analysis to quantify the frequencies of B-cell subsets, T-cell subsets, and myeloid subsets in the periphery in vehicle- and DMH1-treated mice. Regarding myeloid subsets, total $\mathrm{CD} 11 \mathrm{~b}^{+}$myeloid cells and $\mathrm{F} 4 / 80^{+}$macrophages were analyzed in the first experiment, and in the second experiment, the frequencies of different DC subsets (lymphoid, myeloid and plasmacytoid) and the macrophage type 2 (M2) phenotype were assessed. After excluding doublets and dead cells, the indicated gating strategies were followed to determine the frequencies of (a) myeloid cells (CD11 bigh events) and macrophages $\left(\mathrm{CD} 11 \mathrm{~b}^{+} \mathrm{F} 4 /\right.$ $80^{+}$events), (b) lymphoid DCs $\left(\mathrm{CD} 11 \mathrm{c}^{\text {high }} \mathrm{CD} 8 \mathrm{a}^{+}\right.$events in the $\mathrm{B} 220^{-} \mathrm{CD} 11 \mathrm{~b}^{+}$population), myeloid DCs $\left(\mathrm{CD} 11 \mathrm{c}^{\text {high }} \mathrm{CD} 8 \mathrm{a}^{-}\right.$events in the $\mathrm{B} 220^{-} \mathrm{CD} 11 \mathrm{~b}^{+}$population) and $\mathrm{pDCs}\left(\mathrm{CD} 11 \mathrm{c}^{\mathrm{int}} \mathrm{CD} 317^{+}\right.$events in the $\mathrm{B} 220^{+} \mathrm{CD} 11 \mathrm{~b}^{-}$population), and (c) M2 macrophages (Ly6C ${ }^{-} \mathrm{CD} 206^{+}$events in the $\mathrm{Ly}_{6 \mathrm{G}^{-}} \mathrm{CD} 11 \mathrm{~b}^{+} \mathrm{F} 4 / 80^{+}$population). (d) Graphs represent the percentages of the studied populations. Data are represented as the mean \pm standard error of the mean (SEM). The statistical analysis was performed with Student's $t$ test. DMH1 = dorsomorphin homologue 1; M2 = macrophage type 2 expression of BMP2 during the initial phases of EAE likely promotes a pro-inflammatory environment rather than controlling the immune response. In addition, BMP2 expression is upregulated in NK cells upon cytokine and TLR-ligand activation and acts in an autocrine manner through the canonical signaling pathway; it serves as an important regulator of NK function, including proliferation, cytokine and chemokine production, DC activation, and cytotoxic activity [22]. In contrast, BMP2 and BMP4 have also been reported to hamper the production of immunoglobulins in stimulated naïve and memory B cells, although they are not the most relevant BMPs that affect B cell function [24]. On the other hand, we can speculate that CNS-infiltrating cells present a pattern of expression similar to that of peripheral immune cells; thus, a local increase in BMP2 in CNS-infiltrating cells could promote the differentiation of glial precursors into astrocytes over oligodendrocytes and thus impede healing of the damaged tissue $[39,40]$. BMP7 inhibits the production of Ig and specifically induces apoptosis of B cells [24] and polarization of macrophages to the M2 alternative phenotype, which is an immunosuppressive phenotype [20]. Consistent with this line of evidence, the administration of BMP7 in inflammatory bowel 

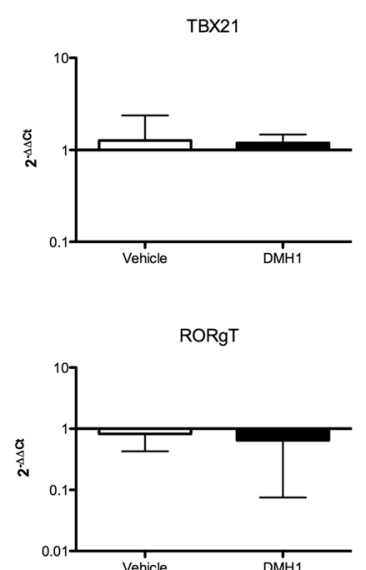

MRC1

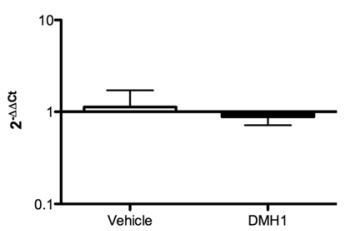

TGFb

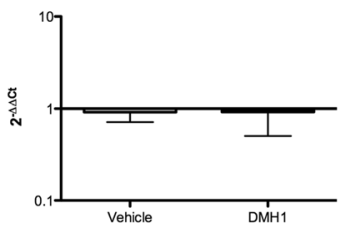

GATA3

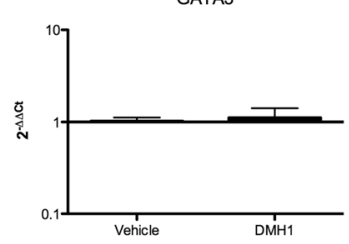

FOXP3

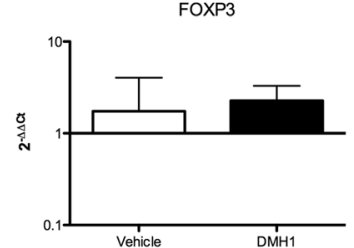

IFNg

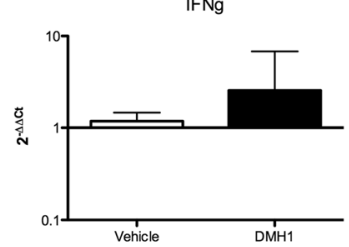

IL10

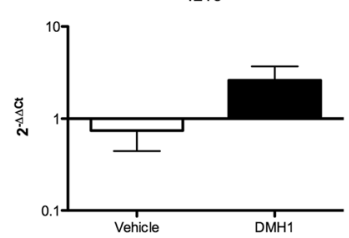

Fig. 6 The expression pattern of Th1/Th2/Th17/regulatory transcription factors and cytokines is not altered in the CNS of DMH1-treated mice. (a) The expression of the transcription factors TBX21 (Th1), GATA3 (Th2), ROR $\gamma \mathrm{T}$ (Th17), and FOXP3 (Treg) and the expression of MRC1 (M2 macrophages), IFN- $\gamma$, TGF- $\beta$, IL-10, IL-4, and IL-17A were analyzed by qPCR in spinal cords of vehicle- and DMH1-treated mice. Six spinal cords from the vehicle group and seven samples from the DMH-1 group were included, except for TBX21 (five samples in the vehicle group) and IL-10 (five samples in the vehicle group and six samples in the DMH1

disease had an anti-inflammatory effect, probably reducing the expression of IL-6 [41]. Thus, the secretion of BMP7 in the peripheral immune system would favor an antiinflammatory milieu. On the other hand, ex vivo BMP7 increased the proliferation of lamina propria mononuclear cells in a model of experimental colitis [42] and has also been identified as a key factor that induces differentiation of Langerhans cells that are highly capable of producing proinflammatory cytokines [43]. In contrast to that of BMP2 and BMP7, the expression of BMP6 completely disappeared upon EAE induction in the majority of mice. BMP6 specifically inhibits plasma cell differentiation and Ig production [24], as well as macrophage proliferation; however, it increases the release of pro-inflammatory mediators (i.e., IL-6, iNOS, and TNF-alpha) in this cell type $[21,44,45]$. Although BMP6 inhibits proliferation of the Jurkat Tag cell line, this

b
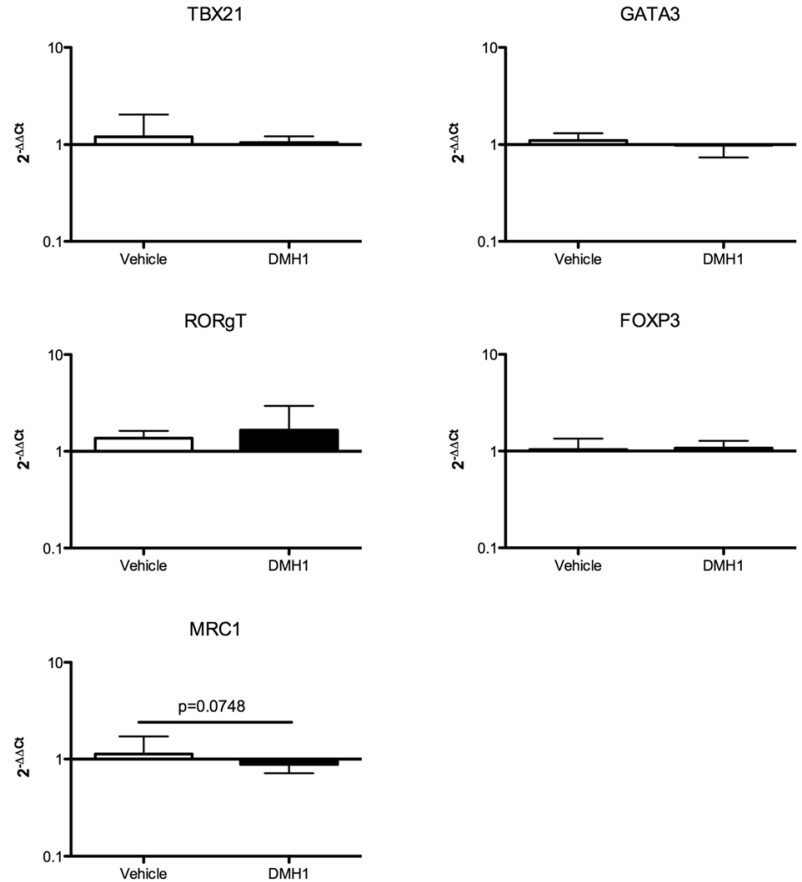

group). (b) The expression of the transcription factors TBX21 (Th1), GATA3 (Th2), ROR $\gamma$ T (Th17), and FOXP3 (Treg) and the expression of MRC1 (M2 macrophages) were analyzed in the inflammatory infiltrate obtained from freshly isolated spinal cords of vehicle- and DMH1-treated mice. Six samples per group were included, with the exception of GATA3 (five samples in the DMH1 group). Data represent the mean \pm standard deviation (SD). Comparisons between means were performed using mixed models

effect is not observed in human $\mathrm{CD}^{+} \mathrm{T}$ cells [46], probably indicating that BMP6 has a prominent role in macrophage function (as a pro-inflammatory agent) and B cell function (as an anti-inflammatory agent) rather than in T-cell function. However, the effect of BMPs on B cells would not be relevant in this EAE model since B cells are not required for EAE development when MOG peptides are used to immunize the mice [47]. For the first time, we describe the expression pattern of BMPs, noggin, and BMPR type II in the immune system during the clinical course of EAE, and our results showed that the expression of the studied proteins in the immune system of EAE mice varied more significantly in the inflammatory phases of the disease (especially in the induction phase), highlighting the BMP signaling pathway as a possible immunoregulatory therapeutic target for the treatment of MS. 


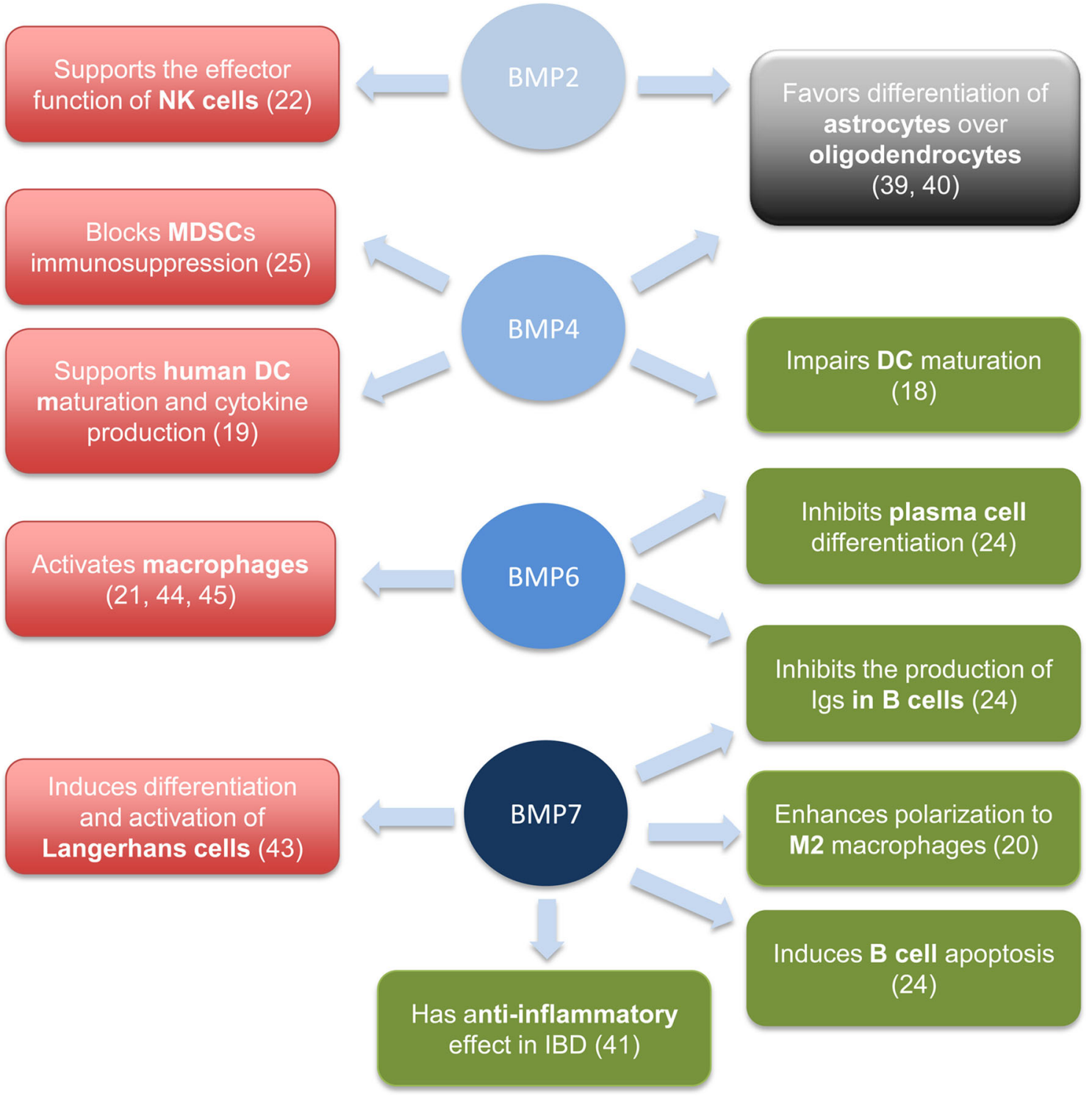

Fig. 7 Diagram of the main functions described for BMPs on the immune system. BMP2, BMP4, BMP6, and BMP7 potentiate the immune response (indicated in the red color boxes) and also have immunosuppressor functions (indicated in the green color boxes). The black color box describes the effect of BMP2 and BMP4 on CNS

In vivo inhibition of the canonical signaling pathway with small inhibitors once the disease was already established reduced EAE severity. DM and DMH1 treatment also ameliorated the histopathologic features of the disease, such as demyelination, inflammation, astrogliosis, and microglia reactivity, in clinically recovered mice. Although we have not studied further events that occur in the CNS, it is well known that BMPs enhance astrogliogenesis over oligodendrogenesis $[39,40]$, thus hampering remyelination and healing of the damaged tissue. As BMPs are increased in MS lesions, especially in the damaged white matter [4], inhibition of the canonical BMP signaling pathway could be responsible for the reduced demyelination and astrogliosis observed in the spinal resident cells involved in remyelination and tissue repair. The cited articles are indicated in brackets. $\mathrm{DC}=$ dendritic cell; IBD $=$ inflammatory bowel disease; $\mathrm{MDSCs}=$ myeloid-derived supressor cells; $\mathrm{NK}=$ natural killer cell

cords of DM- and DMH1-treated mice. However, it is difficult to determine whether this effect is the cause or consequence of clinical amelioration; in mice that experienced a recovery in the clinical score, we also found smaller numbers of infiltrating inflammatory cells, which are mostly responsible for myelin destruction. In fact, we have no data on the ability of DM and DMH1 to cross the blood-brain barrier (BBB), so we cannot rule out the possibility that the small molecules DM and DMH1 inhibit the BMP signaling pathway directly in CNS-resident cells. On the other hand, clinical recovery could also be a consequence of the reduction of the inflammatory infiltrate itself rather than a direct effect of DM or DMH1 on peripheral immune cells or CNS-resident cells. Therefore, 
fewer infiltrating inflammatory cells would secrete smaller amounts of BMPs into the CNS, for example, favoring the differentiation of oligodendrocytes and favoring remyelination processes as a consequence.

We performed ex vivo studies with samples of DMH1treated mice since DMH1 is a more selective inhibitor of BMP signaling than DM and does not interfere with other pathways. Treatment with the BMP signaling inhibitor DMH1 did not alter the gene expression of Th1, Th2, Th17, or Treg transcription factors or the expression of their prototypic cytokines in the spinal cords of EAE mice or in the inflammatory infiltrate, suggesting that BMPs are not relevant for the immune response of CNS-resident cells when the disease is already established. However, MCR1 gene expression was decreased in the inflammatory infiltrate of DMH1-treated mice, and consistently, the percentage of M2 macrophages was lower in the peripheral immune system of DMH1treated mice. Accordingly, BMP7 has been reported to induce M2 macrophage polarization [20]. On the other hand, no significant changes were detected in the frequency of other peripheral immune populations, except for DCs. While classic DCs were slightly decreased in treated mice, pDCs increased in the periphery of DMH1-treated mice. pDCs are the major producers of type I IFNs, including IFN- $\beta$, which was the first disease-modifying treatment approved for relapsing MS [48], and they have tolerogenic properties $[49,50]$. However, the role of pDCs in EAE is controversial: while the depletion of $\mathrm{pDC}$ at the time of EAE induction ameliorated the disease by hampering the development of MOG-specific Th17-T cells in the spleen, the elimination of pDCs at the peak of the disease exacerbated clinical symptoms [51, 52]. In addition, pDCs play an important role as antigen-presenting cells that present myelin-derived autoantigens and regulate the induction of EAE by promoting the expansion of antigen-specific Tregs [53]. Consistent with this line of evidence, transfer of MOGloaded pDCs was capable of inducing remission of already established EAE symptoms [54]. However, we cannot be sure that the increase in peripheral pDCs is the major mechanism responsible for EAE amelioration upon BMP signaling inhibition, since BMPs have multiple functions in the regulation of both immune responses and CNS damage and repair.

In summary, the major changes in the expression of BMPs during the EAE clinical course took place before the onset of the disease (induction phase), when Th-cell populations had already differentiated. Overall, our results suggest that BMP signaling may enhance the differentiation of proinflammatory Th-cell subsets but that BMPs are not involved in the maintenance of the immune response, at least via signaling through Alk2 (or ACVRI) and Alk3 (or BMPR1a). To assess the involvement of BMPs in the initiation of EAE, the BMP signaling pathway should be inhibited at the time of EAE induction; however, this early therapeutic approach is not translatable to MS patients.
Acknowledgments This work was supported by the Fondo de Investigación Sanitaria, Instituto de Salud Carlos III, and co-funded by the European Union (European Regional Development Fund/European Social Fund) "A way to build Europe" under grant PI12/02144.

Required Author Forms Disclosure forms provided by the authors are available with the online version of this article.

\section{References}

1. Nohe A, Hassel S, Ehrlich M, et al. The mode of bone morphogenetic protein (BMP) receptor oligomerization determines different BMP-2 signaling pathways. The Journal of biological chemistry. 2002;277(7):5330-8.

2. Massague J, Seoane J, Wotton D. Smad transcription factors. Genes \& development. 2005;19(23):2783-810.

3. Eixarch H, Calvo-Barreiro L, Montalban X, Espejo C. Bone morphogenetic proteins in multiple sclerosis: Role in neuroinflammation. Brain Behav Immun. 2018;68:1-10.

4. Costa C, Eixarch H, Martinez-Saez E, et al. Expression of Bone Morphogenetic Proteins in Multiple Sclerosis Lesions. Am J Pathol. 2019;189(3):665-76.

5. Penn M, Mausner-Fainberg K, Golan M, Karni A. High serum levels of BMP-2 correlate with BMP-4 and BMP-5 levels and induce reduced neuronal phenotype in patients with relapsingremitting multiple sclerosis. Journal of neuroimmunology. 2017;310:120-8.

6. Mausner-Fainberg K, Urshansky N, Regev K, Auriel E, Karni A. Elevated and dysregulated bone morphogenic proteins in immune cells of patients with relapsing-remitting multiple sclerosis. Journal of neuroimmunology. 2013;264(1-2):91-9.

7. Urshansky N, Mausner-Fainberg K, Auriel E, Regev K, Bornstein NM, Karni A. Reduced production of noggin by immune cells of patients with relapsing-remitting multiple sclerosis. Journal of neuroimmunology. 2011;232(1-2):171-8.

8. Urshansky N, Mausner-Fainberg K, Auriel E, Regev K, Karni A. Low and dysregulated production of follistatin in immune cells of relapsing-remitting multiple sclerosis patients. Journal of neuroimmunology. 2011;238(1-2):96-103.

9. Sospedra M, Martin R. Immunology of Multiple Sclerosis. Semin Neurol. 2016;36(2):115-27.

10. Christiansen JH, Coles EG, Wilkinson DG. Molecular control of neural crest formation, migration and differentiation. Curr Opin Cell Biol. 2000;12(6):719-24.

11. Revest JM, Suniara RK, Kerr K, Owen JJ, Dickson C. Development of the thymus requires signaling through the fibroblast growth factor receptor R2-IIIb. J Immunol. 2001;167(4): 1954-61.

12. Bleul CC, Boehm T. BMP signaling is required for normal thymus development. J Immunol. 2005;175(8):5213-21.

13. Cejalvo T, Sacedon R, Hernandez-Lopez C, et al. Bone morphogenetic protein-2/4 signalling pathway components are expressed in the human thymus and inhibit early T-cell development. Immunology. 2007;121(1):94-104.

14. Lu L, Ma J, Wang X, et al. Synergistic effect of TGF-beta superfamily members on the induction of Foxp3+ Treg. European journal of immunology. 2010;40(1):142-52.

15. Yoshioka Y, Ono M, Osaki M, Konishi I, Sakaguchi S. Differential effects of inhibition of bone morphogenic protein (BMP) signalling on T-cell activation and differentiation. European journal of immunology. 2012;42(3):749-59.

16. Kuczma M, Kurczewska A, Kraj P. Modulation of bone morphogenic protein signaling in T-cells for cancer immunotherapy. Journal of immunotoxicology. 2014;11(4):319-27. 
17. Martinez VG, Sacedon R, Hidalgo L, et al. The BMP Pathway Participates in Human Naive CD4+ T Cell Activation and Homeostasis. PloS one. 2015;10(6):e0131453.

18. Pluchino S, Zanotti L, Brambilla E, et al. Immune regulatory neural stem/precursor cells protect from central nervous system autoimmunity by restraining dendritic cell function. PloS one. 2009;4(6):e5959.

19. Martinez VG, Hernandez-Lopez C, Valencia J, et al. The canonical BMP signaling pathway is involved in human monocyte-derived dendritic cell maturation. Immunol Cell Biol. 2011;89(5):610-8.

20. Rocher C, Singla DK. SMAD-PI3K-Akt-mTOR pathway mediates BMP-7 polarization of monocytes into M2 macrophages. PloS one. 2013;8(12):e84009.

21. Lee GT, Kwon SJ, Lee JH, et al. Induction of interleukin-6 expression by bone morphogenetic protein- 6 in macrophages requires both SMAD and $\mathrm{p} 38$ signaling pathways. The Journal of biological chemistry. 2010;285(50):39401-8.

22. Robson NC, Hidalgo L, Mc Alpine T, et al. Optimal effector functions in human natural killer cells rely upon autocrine bone morphogenetic protein signaling. Cancer Res. 2014;74(18):5019-31.

23. Kersten C, Sivertsen EA, Hystad ME, Forfang L, Smeland EB, Myklebust JH. BMP-6 inhibits growth of mature human B cells; induction of Smad phosphorylation and upregulation of Id1. BMC immunology. 2005;6:9.

24. Huse K, Bakkebo M, Oksvold MP, et al. Bone morphogenetic proteins inhibit CD40L/IL-21-induced Ig production in human $\mathrm{B}$ cells: differential effects of BMP-6 and BMP-7. European journal of immunology. 2011;41(11):3135-45.

25. Cao Y, Slaney CY, Bidwell BN, et al. BMP4 inhibits breast cancer metastasis by blocking myeloid-derived suppressor cell activity. Cancer Res. 2014;74(18):5091-102.

26. Ara J, See J, Mamontov P, et al. Bone morphogenetic proteins 4, 6, and 7 are up-regulated in mouse spinal cord during experimental autoimmune encephalomyelitis. J Neurosci Res. 2008;86(1):125-35.

27. Hao J, Ho JN, Lewis JA, et al. In vivo structure-activity relationship study of dorsomorphin analogues identifies selective VEGF and BMP inhibitors. ACS Chem Biol. 2010;5(2):245-53.

28. Gutierrez-Franco A, Eixarch H, Costa C, et al. Semaphorin 7A as a Potential Therapeutic Target for Multiple Sclerosis. Mol Neurobiol. 2017;54(6):4820-31.

29. Baker D, Amor S. Publication guidelines for refereeing and reporting on animal use in experimental autoimmune encephalomyelitis. Journal of neuroimmunology. 2012;242(1-2):78-83.

30. Ali JL, Lagasse BJ, Minuk AJ, et al. Differential cellular responses induced by dorsomorphin and LDN-193189 in chemotherapysensitive and chemotherapy-resistant human epithelial ovarian cancer cells. Int J Cancer. 2015;136(5):E455-69.

31. Ivanov, II, Atarashi K, Manel N, et al. Induction of intestinal Th17 cells by segmented filamentous bacteria. Cell. 2009;139(3):485-98.

32. Livak KJ, Schmittgen TD. Analysis of relative gene expression data using real-time quantitative PCR and the 2(-Delta Delta C(T)) Method. Methods. 2001;25(4):402-8.

33. Bustin SA, Benes V, Garson JA, et al. The MIQE guidelines: minimum information for publication of quantitative real-time PCR experiments. Clin Chem. 2009;55(4):611-22.

34. Zhou G, Myers R, Li Y, et al. Role of AMP-activated protein kinase in mechanism of metformin action. J Clin Invest. 2001;108(8):1167-74.

35. Bhatia $\mathrm{M}$, Bonnet $\mathrm{D}, \mathrm{Wu} \mathrm{D}$, et al. Bone morphogenetic proteins regulate the developmental program of human hematopoietic stem cells. The Journal of experimental medicine. 1999;189(7):1139-48.

36. Hidalgo L, Martinez VG, Valencia J, et al. Expression of BMPRIA on human thymic NK cell precursors: role of BMP signaling in intrathymic NK cell development. Blood. 2012;119(8):1861-71.

37. Gazzerro E, Gangji V, Canalis E. Bone morphogenetic proteins induce the expression of noggin, which limits their activity in cultured rat osteoblasts. J Clin Invest. 1998;102(12):2106-14.
38. Mueller TD. Mechanisms of BMP-Receptor Interaction and Activation. Vitamins and hormones. 2015;99:1-61.

39. Mabie PC, Mehler MF, Marmur R, Papavasiliou A, Song Q, Kessler JA. Bone morphogenetic proteins induce astroglial differentiation of oligodendroglial-astroglial progenitor cells. The Journal of neuroscience : the official journal of the Society for Neuroscience. 1997;17(11):4112-20.

40. Grinspan JB, Edell E, Carpio DF, et al. Stage-specific effects of bone morphogenetic proteins on the oligodendrocyte lineage. Journal of neurobiology. 2000;43(1):1-17.

41. Maric I, Poljak L, Zoricic S, et al. Bone morphogenetic protein-7 reduces the severity of colon tissue damage and accelerates the healing of inflammatory bowel disease in rats. J Cell Physiol. 2003;196(2):258-64.

42. Maric I, Kucic N, Turk Wensveen T, et al. BMP signaling in rats with TNBS-induced colitis following BMP7 therapy. Am J Physiol Gastrointest Liver Physiol. 2012;302(10):G1151-62.

43. Yasmin N, Bauer T, Modak M, et al. Identification of bone morphogenetic protein 7 (BMP7) as an instructive factor for human epidermal Langerhans cell differentiation. The Journal of experimental medicine. 2013;210(12):2597-610.

44. Hong JH, Lee GT, Lee JH, et al. Effect of bone morphogenetic protein6 on macrophages. Immunology. 2009;128(1 Suppl):e442-50.

45. Kwon SJ, Lee GT, Lee JH, Kim WJ, Kim IY. Bone morphogenetic protein-6 induces the expression of inducible nitric oxide synthase in macrophages. Immunology. 2009;128(1 Suppl):e758-65.

46. Sivertsen EA, Huse K, Hystad ME, Kersten C, Smeland EB, Myklebust JH. Inhibitory effects and target genes of bone morphogenetic protein 6 in Jurkat TAg cells. European journal of immunology. 2007;37(10):2937-48.

47. Svensson L, Abdul-Majid KB, Bauer J, Lassmann H, Harris RA, Holmdahl R. A comparative analysis of B cell-mediated myelin oligodendrocyte glycoprotein-experimental autoimmune encephalomyelitis pathogenesis in B cell-deficient mice reveals an effect on demyelination. European journal of immunology. 2002;32(7):1939-46.

48. Jacobs LD, Cookfair DL, Rudick RA, et al. Intramuscular interferon beta-1a for disease progression in relapsing multiple sclerosis. The Multiple Sclerosis Collaborative Research Group (MSCRG). Ann Neurol. 1996;39(3):285-94.

49. Swiecki M, Colonna M. Unraveling the functions of plasmacytoid dendritic cells during viral infections, autoimmunity, and tolerance. Immunol Rev. 2010;234(1):142-62.

50. Chistiakov DA, Orekhov AN, Sobenin IA, Bobryshev YV. Plasmacytoid dendritic cells: development, functions, and role in atherosclerotic inflammation. Front Physiol. 2014;5:279.

51. Isaksson M, Ardesjo B, Ronnblom L, et al. Plasmacytoid DC promote priming of autoimmune Th17 cells and EAE. European journal of immunology. 2009;39(10):2925-35.

52. Bailey-Bucktrout SL, Caulkins SC, Goings G, Fischer JA, Dzionek A, Miller SD. Cutting edge: central nervous system plasmacytoid dendritic cells regulate the severity of relapsing experimental autoimmune encephalomyelitis. J Immunol. 2008;180(10):6457-61.

53. Irla M, Kupfer N, Suter T, et al. MHC class II-restricted antigen presentation by plasmacytoid dendritic cells inhibits $\mathrm{T}$ cellmediated autoimmunity. The Journal of experimental medicine. 2010;207(9):1891-905.

54. Duraes FV, Lippens C, Steinbach K, et al. pDC therapy induces recovery from EAE by recruiting endogenous $\mathrm{pDC}$ to sites of CNS inflammation. J Autoimmun. 2016;67:8-18.

Publisher's Note Springer Nature remains neutral with regard to jurisdictional claims in published maps and institutional affiliations. 